\title{
MACROECONOMIC ADJUSTMENT AND THE POOR: ANALYTICAL ISSUES AND CROSS-COUNTRY EVIDENCE
}

\author{
Pierre-Richard Agénor \\ The World Bank Washington DC
}

\begin{abstract}
This paper studies the links between macroeconomic adjustment and poverty. The first part summarizes some of the recent evidence on poverty in the developing world. The second reviews the various channels through which macroeconomic policies affect the poor, whereas the third is devoted to the specific role of the labor market. It presents an analytical framework that captures some of the main features of the urban labor market in developing countries and studies the effects of fiscal adjustment on wages, employment, and poverty. The fourth part presents cross-country regressions linking various macroeconomic and structural variables to poverty. Higher levels and growth rates of per capita income, higher rates of real exchange rate depreciation, better health conditions, and a greater degree of commercial openness lower poverty, whereas inflation, greater income inequality, and macroeconomic volatility tend to increase it. Moreover, the impact of growth on poverty appears to be asymmetric; it seems to result from a significant relationship between episodes of increasing poverty and negative growth rates.
\end{abstract}

Keywords. Macroeconomic policy; Poverty; Labor markets

\section{Introduction}

Understanding and assessing the poverty and distributional effects of macroeconomic adjustment programs remain issues of considerable importance for economists and policymakers alike. A key reason for this is the growing evidence that economic and financial crises hurt the poor the most, because they often lack the means to protect themselves from adverse income and employment shocks. The poor lack assets (such as land and bank deposits) and often have no direct access to credit markets (or face prohibitive borrowing costs when they do), to smooth the impact of these shocks. For the very poor, unfavorable shocks may be large enough to result in actual declines in consumption, bringing it down below subsistence levels and exerting a detrimental effect on their longer term nutrition and health prospects. Moreover, due to the lack of education and marketable skills, the poor tend to be less mobile (across sectors and regions) than 
better-educated workers and are therefore often unable to switch jobs and capitalize on available employment opportunities. Finally, indirect sources of income and public transfers other than unemployment benefits may decline during crises, because during such episodes the ability of relatives (or local communities) to engage in resource sharing and income redistribution may be reduced, while at the same time governments may be forced to adjust drastically their fiscal accounts with across-the-board cuts in expenditure.

There is also growing recognition of the fact that assessing the impact of adjustment programs on the poor may entail dynamic trade-offs. In particular, it is now well recognized that the large budgetary cuts that have been associated in some cases with stabilization efforts have fallen to a significant extent on transfers to households and other types of social expenditure, thereby worsening the plight of lower-income groups in the short term. At the same time, however, it is also well understood that these groups tend to be the ones most adversely affected by rapid inflation, credit rationing, and high interest rates, in part because of the effect of these variables on private sector activity and employment. To the extent that fiscal austerity leads to a durable reduction in the rate of inflation, greater access to credit by private firms, and lower borrowing rates, the poor may benefit from government spending cuts in the longer run. It is therefore important to carefully evaluate the net benefits (in present value terms) that such trade-offs entail in designing adjustment programs.

Despite the importance of these issues, however, the evidence examining the impact of adjustment programs (and macroeconomic policies in particular) on the poor remains relatively limited. Various country- (or region-) specific studies have been published in recent years, but they often remain highly descriptive when it comes to assessing the effect of macroeconomic and other structural variables on poverty. In addition, although it is well recognized that the poor often generate a sizable share of their income from wage employment, the role of the labor market in the transmission of macroeconomic policy shocks to lower-income groups (particularly those located in the urban sector) has not been fully explored in analytical and empirical models. Understanding this role is all the more important given the peculiarities and imperfections (which often result from government intervention) that often characterize the labor market in developing countries.

The present study attempts to contribute to the current debate at three levels. First, it provides an analytical overview of the various transmission channels of macroeconomic policy to the poor, dwelling in the process on the most recent analytical and empirical literature in this area. Second, it provides a formal analysis of the role of the labor market in the transmission of policy shocks to the urban poor, taking into account the type of distortions often observed in the developing world. Although the model is used to examine only the effect of a particular shock, it is sufficiently general to serve a variety of purposes. Third, it provides some new, quantitative evidence on the effect of macroeconomic factors on poverty, based on cross-country regressions.

The remainder of the paper is organized as follows. Section II provides a brief review of the recent evidence on poverty in developing countries. The various

(C) Blackwell Publishing Ltd. 2004 
channels through which macroeconomic policies affect the poor are discussed in Section III. Both direct and indirect effects (through, for instance, inflation, aggregate demand, income distribution, and macroeconomic volatility), are analyzed. The role of the labor market is also discussed in general terms. Section IV develops an analytical framework that captures in a more formal way the role of the urban labor market in the transmission mechanism of macroeconomic policy shocks. The model incorporates several important and well-documented features of the labor market in developing countries, such as efficiency wages, a large informal sector, labor market segmentation, a heterogeneous and imperfectly mobile labor force, and wage flexibility in the informal economy. ${ }^{1}$ The impact and steady-state effects of an increase in taxes - a typical measure in adjustment programs - are also examined. Section V provides cross-section econometric evidence on the impact of macroeconomic and structural variables on poverty, including the degree of openness, school enrollment rates, real exchange rate depreciations, macroeconomic volatility, income inequality, and asymmetric movements in income levels and output growth. Finally, Section VI summarizes the main results of the analysis and elaborates on its policy implications.

\section{Poverty: A Brief Overview}

It is now well recognized that poverty is a multidimensional concept, encompassing not only insufficient income but also lack of access to adequate health services and sanitation, a high degree of illiteracy, and deprivation of basic rights and security (see World Bank, 2000). These dimensions of human deprivation interact in many important ways; for instance, improvements in health conditions lead to higher productivity and enhance the ability of workers to increase their incomes. Nevertheless, the focus of this brief overview will be limited to income poverty.

Figure 1 shows the evolution of poverty in various regions of the developing world during the period 1987-98. The indicator displayed is the headcount index (the proportion of individuals or households earning less than a given absolute level of income, or poverty line), which measures the incidence of poverty. ${ }^{2}$ Extreme poverty (defined as living on less than $\$ 1$ per day) is shown on the lefthand side, whereas relative poverty (defined as the share of people living on less than \$2 per day) is shown on the right-hand side. Both indicators depict a similar picture. The incidence of poverty is the highest in South Asia and sub-Saharan Africa. In sub-Saharan Africa, poverty has in fact increased slightly. Indeed, following a significant improvement in living standards during the 1970s and 1980s, extreme poverty declined only slowly in the developing world during the 1990s. The share of the world population living on less than $\$ 1$ a day fell from $28 \%$ in 1987 to $23 \%$ in 1998 , but the number of poor people remained roughly constant as the population increased. The share of people living on less than $\$ 2$ per day (a more relevant threshold for middle-income economies such as those of East Asia and Latin America) showed roughly similar trends. At the same time, progress in alleviating poverty has been far from even across regions; in fact,

(C) Blackwell Publishing Ltd. 2004 


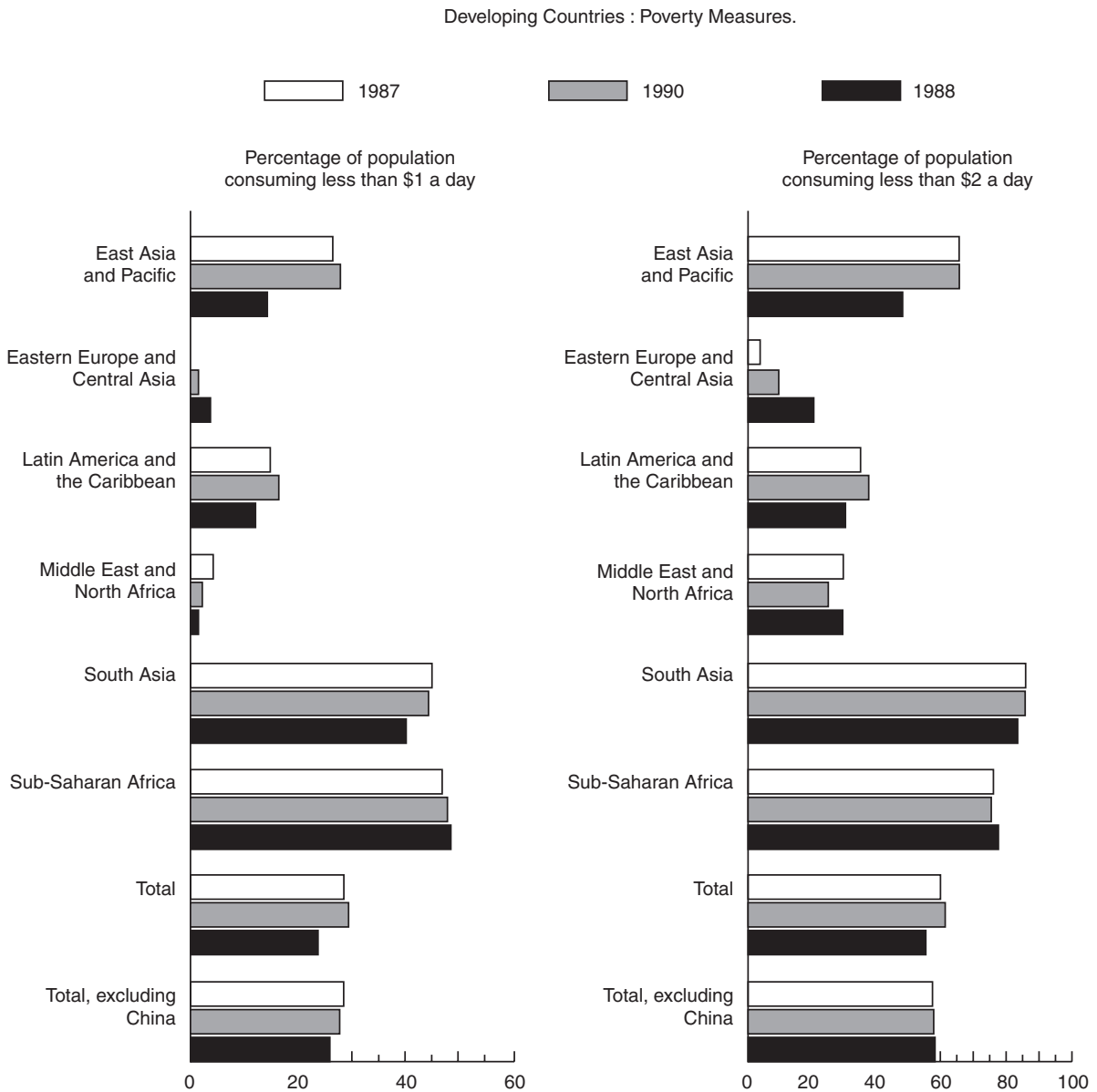

Figure 1. Developing Countries: Poverty Measures.

Source: World Bank.

apart from East Asia, little progress has been achieved during the period in reducing poverty rates. Between 1987 and 1998, poverty rose rapidly in Eastern Europe and Central Asia, and continued to rise (albeit at a relatively low rate) in sub-Saharan Africa. In East Asia, the proportion of people in poverty (both extreme and relative) declined dramatically during the same period, despite the fact that the 1997-98 financial crisis slowed progress considerably. But in South Asia, where a significant propotion of the world's poor live, progress has been much less significant. And in Latin America, although the share of the population in poverty fell during the 1990s, the absolute number of poor people increased to 181 million (of which 90 million live in extreme poverty) in 1998, as a result of population growth (Wodon et al., 2001).

\footnotetext{
(C) Blackwell Publishing Ltd. 2004
} 


\subsection{Rural and Urban Poverty}

The recent evidence also suggests that the distribution of the poor between rural and urban areas varies considerably across regions. This is particularly well illustrated by comparing Latin America and sub-Saharan Africa. In a country like Chile, for instance, poverty is evenly distributed between rural and urban areas (Anríquez et al., 1998). By contrast, in sub-Saharan Africa, the poor tend to be concentrated in rural areas. According to the data compiled by Sahn et al. (1997, ch. 2), for instance, the share of the national poverty rate accounted for by rural areas in the late 1980s and early 1990s was 66\% in Gambia, 72\% in Ghana, $90 \%$ in Kenya and Tanzania, $88 \%$ in Madagascar, $98 \%$ in Malawi, and $71 \%$ in Zambia. ${ }^{3}$ According to World Bank estimates, three-fourths of the poor in Côte d'Ivoire in 1995 were located in rural areas (World Bank, 1997, p. 11). At the same time, in many countries in sub-Saharan Africa - where both population and urbanization growth rates tend to be relatively high, compared to other regions of the developing world - the regional distribution of poverty in the past few years has been substantially affected by rapid rural-to-urban migration. In several cases, urban poverty, although not as severe as it is in rural areas, has become a major source of public concern. In Ghana for instance, the rural poverty rate was $34 \%$ in 1992 , whereas the urban poverty rate was $26.5 \%$ (Canagarapajah and Mazumdar, 1997). Although rural poverty declined sharply between 1987 and 1992, little progress was achieved in reducing urban poverty during that period.

The sources of income of the rural poor and the urban poor also differ significantly. The rural poor in many countries in sub-Saharan Africa, for instance, are predominantly self-employed and continue to rely on direct earnings from agricultural production as their main source of income - although income from salaried employment and self-employment in small enterprises have become important in some countries. ${ }^{4}$ The data compiled by Sahn et al. (1997) indicate that in countries like Côte d'Ivoire, Ghana, Guinea, Madagascar, and Tanzania, more than $90 \%$ of the rural workers were self-employed in the early 1990s, reflecting the predominance of own-account agriculture and, to a much lesser extent, small and micro enterprises in manufacturing and services. By contrast, the urban poor are typically selfemployed workers in very small enterprises in the informal (nonwage) sector; but their incomes tend to fluctuate in response to changes in activity in the formal economy, because of the ease of entry in the informal sector and the degree of mobility of the labor force between the two sectors.

The distribution of poor households between rural and urban areas has important implications for studies aimed at assessing the effect of short-term stabilization policies on poverty. Income characteristics suggest, for instance, that the rural poor may be less vulnerable, and the urban poor more vulnerable, to some types of macroeconomic policy shocks. The reason is that, unlike the urban poor, the rural poor can cushion the impact of an adverse shock to income on consumption by adjusting the share of their agricultural output that they keep for themselves. ${ }^{5}$ At the same time, the urban poor tend to benefit more than the 
rural poor from food subsidies. Thus, large cuts in government subsidies may have a larger effect on the urban poor. This reasoning would suggest that studies focusing on the effects of macroeconomic adjustment on the poor may need to analyze separately the behavior of urban and rural poverty rates, with macroeconomic variables possibly playing a less significant role in the former case.

\subsection{Poverty, Growth, and Inequality}

Figures 2 and 3 show the relationship between growth (as measured by the annual rate of change of real GNP per capita) and two measures of poverty during the 1990s: the headcount index (defined in the previous section) and the poverty gap index (defined as the average shortfall of the income of the poor with respect to the poverty line, multiplied by the headcount index), which measures the depth of poverty. Both extreme and relative poverty measures are used. The figures show no obvious pattern in the relation between growth and poverty. One reason that may explain this result is that growth during the period was accompanied by significant changes in income distribution: while poverty could fall fairly rapidly with distributionally-neutral growth (possibly one to one, as Dollar and Kraay (2001) claim to have found), it takes only small deviations from neutrality to wipe out those gains.

Latin America is a case in point. A recent study by Székely (2001) found that in 12 out of the 17 countries with available data in the region, moderate poverty did decline during the 1990s (with Chile, the Dominican Republic, Panama, Uruguay and Brazil recording the largest reductions). But poverty increased in Peru, Mexico, Nicaragua, Venezuela, and El Salvador. In Latin America as a whole, the share of poor people declined by 10\% between 1990 and 1999 . However, no country in Latin America for which data on income distribution are available shows a decline in income inequality during the 1990s. Had inequality remained unchanged, poverty would have declined by more than it actually did. Growth would have lifted 90 million of individuals out of poverty, instead of 45 million. Thus, income inequality swept away many of the benefits of recent economic growth for large sectors of society in the region.

In Mexico, for instance, between 1996 and 1998, GDP per capita increased by $9.7 \%$ in real terms. However, poverty barely declined during that period. In fact, the incomes of the poorest $30 \%$ of the population actually fell. The increase in mean income was due entirely to income gains among the richest 30\% (particularly the richest $10 \%$ ) of the population. Another example is Chile. Between 1992 and 1996, GDP per capita increased by more than 30\% in real terms. During the same period, moderate poverty (as defined above) declined from $20 \%$ to $16 \%$ - a $20 \%$ reduction in the proportion of poor. However, income inequality also increased during the period. ${ }^{6}$ Had the distribution of income remained the same as in 1992, the proportion of poor would have actually declined to $10 \%$, rather than $16 \%$. The poverty rate would have been cut in half, instead of by $20 \%$. The link between poverty, growth, and inequality will be examined in the next sections, from both analytical and empirical standpoints.

(C) Blackwell Publishing Ltd. 2004 

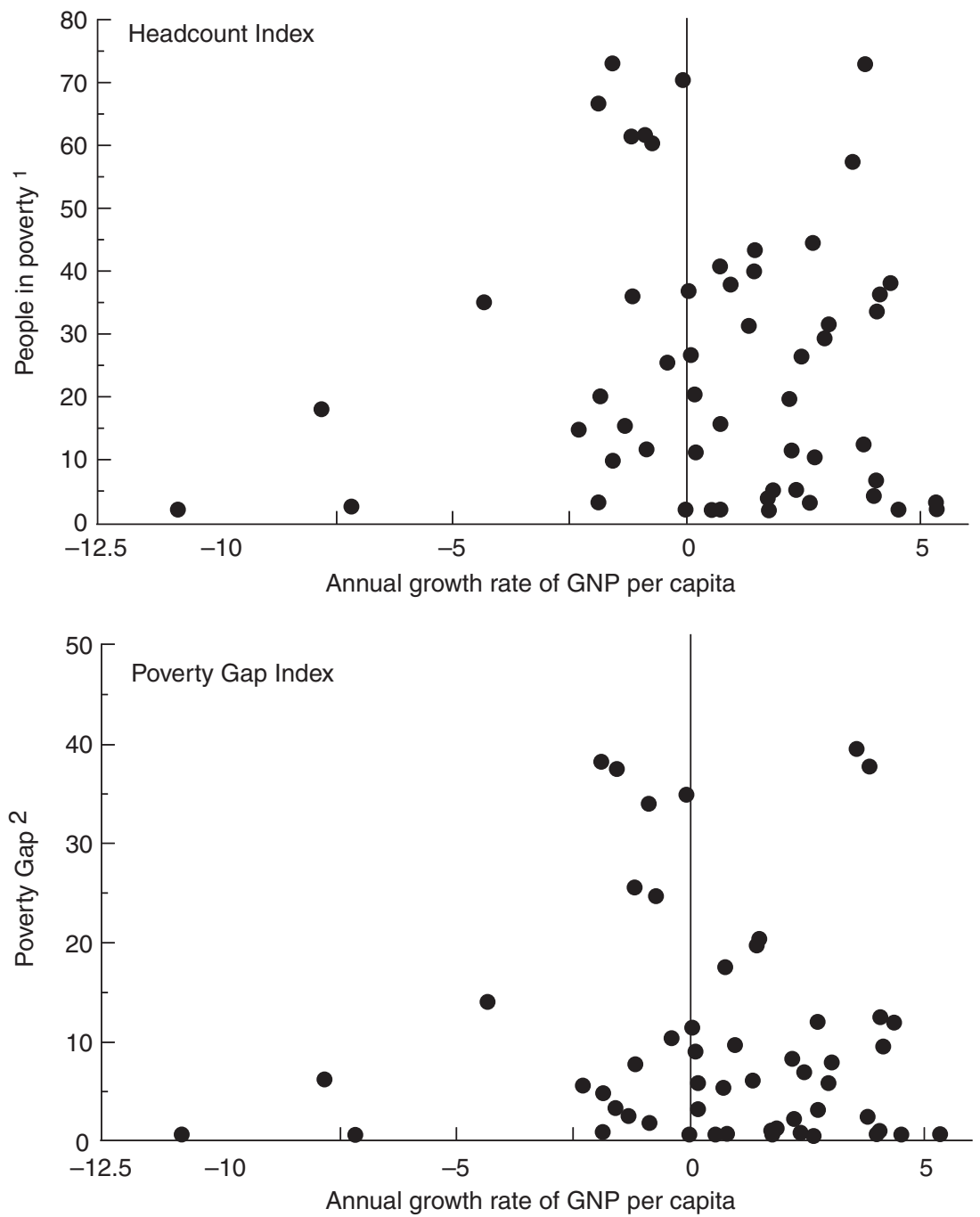

Figure 2. Developing Countries: Growth and People in Absolute Poverty (in percent).

Source: Table 4 in World Bank, World Development Report $(2000 / 2001)$. ${ }^{1}$ Proportion of the population earning US\$1 or less a day, various survey years. ${ }^{2}$ Poverty gap at US\$1 or less a day, various survey years.

Note: Sample consists of 54 countries for which data are provided in the World Development Report.

\section{Transmission Channels}

Much progress has been achieved in recent years in understanding the various channels through which macroeconomic policy shocks are transmitted to output, employment, wages, and prices in a developing-country context (for an overview, 

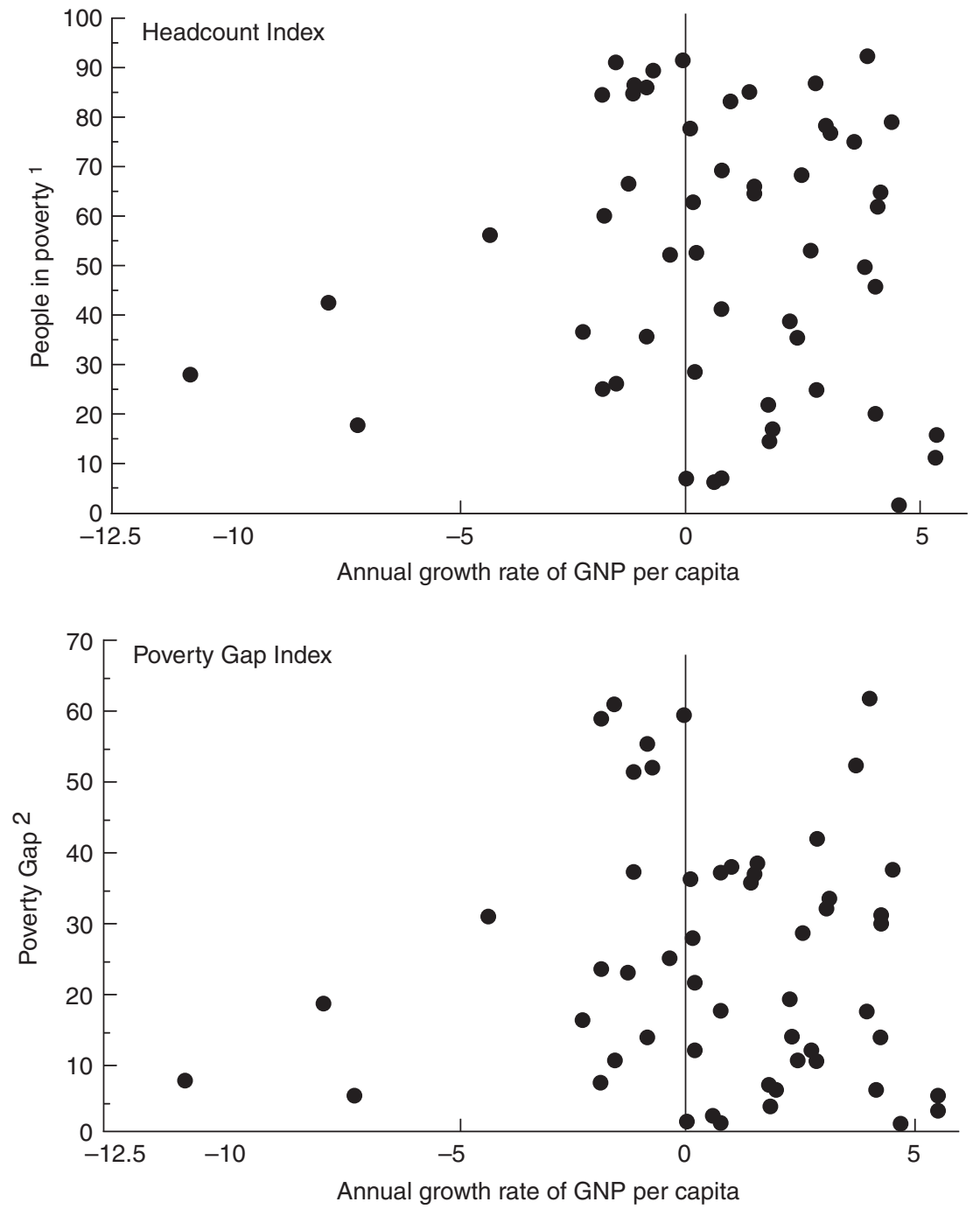

Figure 3. Developing Countries: Growth and People in Relative Poverty (in percent).

Source: Table 4 in World Bank, World Development Report (2000/2001). ${ }^{1}$ Proportion of the population earning US\$2 or less a day, various survey years. ${ }^{2}$ Poverty gap at US\$2 or less a day, various survey years.

Note: Sample consists of 54 countries for which data are provided in the World Development Report.

see Agénor and Montiel, 1999). Several of these channels are relevant for understanding the impact of macro shocks on the poor, in both rural and urban areas. This section identifies these various channels, dwelling on a distinction between direct and indirect effects. 


\subsection{Direct Effects}

The most direct channels through which macroeconomic adjustment programs affect the poor are public sector layoffs and freezes on the wage bill, cuts in government expenditure on transfers and subsidies, and increases in public sector prices. ${ }^{7}$

\subsubsection{Wage freeze, Layoffs, and Spending Cuts}

Fiscal consolidation often take the form of cuts in real wages in the public sector (for instance, by freezing the nominal wage bill in a context of non-zero inflation) and laying off employees. Wage cuts and layoffs may raise directly the poverty rate, particularly in the absence of a safety net (such as a government-run unemployment benefits scheme) or if they occur during periods of low activity (and thus low demand for labor). A cut in current transfers to low-income households reduces their resources directly, whereas a reduction in subsidies on goods and services (such as basic food items and gasoline) that are consumed by the poor lowers their purchasing power. ${ }^{8}$ Both measures may worsen poverty by forcing households to reduce consumption, with the effect of the latter depending on the expenditure pattern of the poor and their ability to dissave (or borrow) to offset the negative income shock. As noted earlier, to the extent that the urban poor benefit more from transfers and subsidies to begin with, urban poverty rates may increase proportionately more.

However, there are various factors suggesting that assessing the effect of macroeconomic policy on the poor by looking only at aggregate indicators of public expenditure may be misleading. First, there is empirical evidence that social expenditure (including spending on education and health) benefits disproportionately upper-income households. For instance, Camargo and Ferreira (2000) found that in Brazil, social expenditures are to a large extent appropriated by the middle classes and the rich. Li et al. (1999), in a study based on a relatively large group of developing countries, found that the share of the richest income quintile in public spending on education, at $28 \%$, was more than double that of the poorest income quintile (13\%). Similar results were obtained by Castro-Leal et al. (1999) for a group of African countries. And in many Latin American countries, social security and social safety nets have long been 'reserved' for the relatively small group of workers in the formal sector and government employees. In such conditions, large cuts in social expenditure may have little impact on the poorest of the poor.

Second, it may be argued that a wage freeze or layoffs of low-productivity workers, to the extent that they lower overall government expenditure and reduce pressures for monetization of the fiscal deficit, may lower inflation and therefore generate an indirect benefit for the poor (see below). The net welfare effect in present value terms, therefore, is ambiguous because of conflicting effects on (current and future) income. Third, in addition to the level effect associated with reductions in public expenditure, there may be a compositional effect: the share of social spending in total government expenditure may actually increase at the same time that overall spending is being cut. ${ }^{9}$ Moreover, transfers and subsidies may fall both as a percentage of GDP and as a percentage of total government expenditure without any adverse effect on poverty if, at the same

(C) Blackwell Publishing Ltd. 2004 
time, improved targeting of social spending takes place - thereby improving the flow of resources actually reaching the poor. Indeed, in some adjustment programs, expenditure reforms have entailed a redirection of health and education expenditures toward basic/preventive health care and primary education (which benefits the poor more than secondary or tertiary education), and an improvement in the targeting of social safety nets - notably by transforming generalized transfers to households into more specific transfers to the very poor.

Clearly, expenditure reallocation continues to be a major issue in the design of adjustment programs - particularly, at the present time, in countries where debt relief, and associated fiscal savings, create new opportunities for reform and improved targeting. The lack of political influence of the poor, and pressures exerted by more powerful interest groups, may well continue to represent major stumbling blocks to pro-poor reallocations. But the point, nevertheless, is that in cases where fiscal consolidation occurs in such a way that it benefits the poor, the net effect of adjustment may be beneficial - even if the overall level of public expenditure falls.

\subsubsection{Increases in Public Sector Prices}

Increases in prices of goods and services produced by the public sector - such as utilities and other types of public services, such as toll roads - often figure prominently in macroeconomic and structural adjustment programs, particularly when large fiscal imbalances prevail at the inception of the program and public enterprises provide large transfers to the government. Because they reduce the purchasing power of the poor (just like cuts in subsidies do), they hurt them directly. By how much poverty rises will depend ultimately on the consumptionexpenditure pattern of the poor and their ability to 'smooth' consumption through dissavings and borrowing. Once again, however, if the increase in public sector prices leads to a lower fiscal deficit and reduced inflationary pressures, the net effect on the poor may be positive in the medium term.

\subsection{Indirect Effects}

Indirect effects of macroeconomic policy on the poor operate through changes in aggregate demand and output (assuming that excess capacity exists initially) and employment in the private sector; changes in the rate of economic growth; changes in inflation and the relevant expenditure price deflator for the poor; changes in the real exchange rate; macroeconomic volatility; and distributional effects. ${ }^{10}$ In addition, output and employment effects associated with stabilization policies may be asymmetric - imparting some degree of 'hysterisis' to the behavior of poverty rates.

\subsubsection{Aggregate Demand and Employment}

Macroeconomic adjustment programs affect aggregate demand and employment (and thus poverty) through various channels. The first category of effects results from reductions in transfers and subsidies (as noted earlier), and cuts in government expenditure other than wages and salaries. In particular, cuts in capital

\footnotetext{
(C) Blackwell Publishing Ltd. 2004
} 
spending (which have longer-run effects as well, as discussed below) have often been large in practice, due to the difficulty of compressing the wage bill. By reducing aggregate demand and the demand for labor, everything else equal, these reductions in public expenditure may increase poverty.

The second category of effects through which macroeconomic policy affects aggregate demand operates through changes in private spending. Specifically, there are several channels through which lower public spending can lead to a reduction in private expenditure:

- If public investment and private sector investment are complementary (particularly with regard to public investment in infrastructure, as the evidence for developing countries gathered by Agénor and Montiel (1999) suggests), a cut in public investment outlays - in addition to its direct effect on aggregate demand noted earlier - may reduce the productivity of the private capital stock at the margin, and thus reduce private expenditure and aggregate demand.

- An increase in direct taxation aimed at reducing fiscal imbalances, such as an increase in tax rates on wages or profits, may reduce private expenditure on consumption and investment, by reducing expected income and the net rate of return on capital.

- Restrictive credit and monetary policies may lower private expenditure on consumption and investment, either directly (if credit availability effects are important) or by raising interest rates (which translate also into a higher cost of capital). ${ }^{11}$

However, there are also several channels through which public expenditure cuts can lead to higher private expenditure:

- As implied by Ricardian equivalence, a reduction in public expenditure (such as a cut in capital spending, as noted earlier) may lead to an equal reduction in perceived future tax liabilities by the private sector, owing to lower financing needs to retire public debt. The present value of future disposable income will increase, resulting in an increase in current private spending. The net effect of a reduction in public spending on aggregate demand would thus be ambiguous. ${ }^{12}$

- The fall in domestic activity associated with a reduction in public spending at the original level of prices and interest rates could also lead to an increase in private expenditure. Suppose that the initial drop in income leads to a reduction in the demand for money, thereby creating excess supply on the money market. If nominal interest rates adjust downward immediately to maintain portfolio equilibrium, interest-sensitive components of aggregate demand would tend to increase, if inflation does not fall in the exact same proportion. Alternatively, if interest rates are slow to adjust, the excess supply of money may cause households to increase current spending in order to lower their real holdings of money balances (real balance effect). The net, general equilibrium effect on aggregate demand would, again, be ambiguous. 
- Even in the absence of a real balance effect, the reduction in financing requirements by the public sector may reduce the cost, or increase the availability, of bank credit to the private sector, thereby increasing private spending and the capacity to produce (if production was, to begin with, constrained by the ability to finance working capital needs).

- If prices are flexible, or if the cut in public spending was foreseen at the time that currently prevailing nominal wage contracts were agreed upon, the domestic price level could fall sufficiently to increase private spending, thereby mitigating the impact of the cut in public spending on total aggregate demand.

The foregoing discussion suggests, therefore, that the effects of macroeconomic adjustment on poverty operating though changes in aggregate demand are less clear-cut than is often thought. Although there are various channels through which such policies may reduce aggregate demand and worsen poverty (by reducing the level of activity and employment), there are also channels through which they may lead to an increase in aggregate demand and lower unemployment. Moreover, to the extent that reductions in aggregate demand associated with macroeconomic policy also lead to a fall in inflationary pressures (as discussed below) they may also benefit the poor.

\subsubsection{Economic Growth}

Macroeconomic policies may affect the poor not only through their impact on the level of output but also its growth rate over time. There are several channels through which this can occur. Sustained reductions in transfer payments from the public sector to the poor may have an adverse effect not only on the level of income of the poor but also on their propensity to save. In turn, lower savings rates may affect negatively the growth rate of output, as emphasized in endogenous growth models (see Agénor, 2000, ch. 11). ${ }^{13}$ Similarly, to the extent that cuts in public sector investment (particularly in infrastructure) may reduce private investment through a complementarity effect, as indicated earlier, they may lower the rate of economic growth. Tax increases encourage evasion and the shifting of activities to the informal economy - so much so that the net impact may be a fall in revenue. As can be inferred from the analysis in Loayza (1996), which dwells on Barro (1990), the loss in tax revenue may reduce in the longer run the government's capacity to invest in infrastructure and thus lower the rate of economic growth if, again, there is complementary between public and private capital formation. In all these cases, by reducing the economy's growth rate, macroeconomic adjustment may have an adverse impact on poverty.

At the same time, however, the lower inflation rates that tend to be associated with macroeconomic adjustment may increase growth rates through their effect on the level and efficiency of investment, as documented in a number of analytical and empirical studies (see, for instance, Choi et al., 1996). Moreover, to the extent that adjustment reduces the degree of macroeconomic volatility (as discussed later), it may also have a positive effect on growth.

\footnotetext{
(C) Blackwell Publishing Ltd. 2004
} 


\subsubsection{Inflation and Expenditure Deflators}

The poor are more vulnerable to inflation than higher-income groups as a result of a variety of factors:

- Their income (wages or income from self-employment) is often defined in nominal terms, and they often do not benefit from indexation mechanisms. In periods of high inflation, therefore, the purchasing power of their resources may fall dramatically. ${ }^{14}$

- They have few inflation hedges - few real assets, such as land, and usually no indexed financial assets - with which to insulate themselves from the effect of price increases.

- Their holdings of cash balances are subject to the inflation tax, which, although not usually accounted for in standard measures of poverty, could have a significant negative effect on the welfare of the poor. ${ }^{15}$

All three factors suggest that inflation stabilization would benefit the poor proportionately more than upper-income groups. However, a number of mitigating factors should be taken into account. First, because the poor allocate a large share of their income (or own production, if they are self-employed in agriculture) to subsistence, what matters is not so much the movement in the overall level of prices but rather the behavior of the prices of the goods and services that the poor consume (that is, a properly-weighted expenditure deflator). If, for instance, basic staple foods account for a large share of expenditure of low-income households, and if the prices of these commodities are kept under control, disinflation may have little impact on the poor. Second, to the extent that disisnflation is accompanied by a sharp drop in aggregate demand and employment (as discussed earlier), the excess supply of labor may lead, everything else equal, to further downward pressure on wages and a worsening of the plight of the poor. Finally, even if reducing inflation has desirable effects in the longer run, the short-run effect may be to worsen poverty if (as also noted earlier) fiscal adjustmtent takes the form of extensive cuts in social programs. Thus, as indicated in the introduction, there may be a dynamic trade-off, which suggests that it is the net present value of a reduction in inflation that needs to be assessed, in order to determine if stabilization from high inflation is indeed beneficial to the poor.

The situation is, in fact, more complicated than that, because lower inflation also contributes indirectly to growth, as shown empirically in studies such as those of Bruno and Easterly (1998) and Sarel (1996). ${ }^{16}$ Higher growth rates increase the level of income per capita, and the higher level of income tends to lower measured poverty rates, in the absence of adverse shifts in inequality (see below). As noted earlier, inflation may affect growth rates through its impact on the level and efficiency of investment. More specifically, suppose that inflation drives a wedge between the marginal returns to real and financial capital. It thus distorts production incentives. The elimination of this distortion increases both the level and the rate of growth of output. In the model developed by Gylfason (1998) - in which 
both real and financial capital are used as inputs in the production process increased price stability improves the efficiency with which capital is utilized, and thus increases the full-employment level of output in the long run; this represents a fairly conventional static output gain. But lower inflation also increases the rate of economic growth in the presence of constant returns to (broad) capital, as emphasized in the new endogenous growth literature (see, for instance, Easterly, 1993). This dynamic gain can be substantial in practice, as suggested by the simulations performed by Gylfason (1996). ${ }^{17}$ Thus, by lowering the level of inflation (and possibly the variability of inflation, as discussed below) and improving the allocation of resources, macroeconomic adjustment promotes growth, thereby enhancing its long-term benefits to the poor.

\subsubsection{Real Exchange Rate}

The combination of exchange rate, fiscal, and monetary policies implemented in macroeconomic adjustment programs often aims at achieving a depreciation of the real exchange rate, in order to foster a reallocation of resources toward the tradables sector. In turn, a real depreciation may affect poverty (and income distribution) through two main channels:

- A real depreciation - brought about either through a nominal depreciation or a fall in the price of nontradable goods - favors consumers of nontradables (such as food, housing and retail services) in general, and the urban poor in particular. However, in practice, a real depreciation is often implemented through a nominal depreciation, which also raises the domestic price of imported goods. To the extent that such goods are consumed by the poor, there is a negative income effect that may offset, at least in part, the relative price effect.

- A real depreciation tends to foster a reallocation of resources toward agricultural export activities, raising the income of export-crop farmers and rural households (see Dorosh and Sahn, 2000). ${ }^{18}$ In countries where the poor are predominantly located in rural areas, a real depreciation will therefore raise incomes and reduce poverty.

However, there are other offsetting supply-side effects of a real exchange rate depreciation that must also be taken into account. Because resources are reallocated toward the tradable sector, the demand for labor in the nontradable sector may fall; lower employment and nominal wages (in the presence of downward rigidity of prices) may translate into a fall in real wages and a higher incidence of poverty. In particular, if the urban poor are also producers of nontraded goods (as is the case in the informal sector), the economy-wide benefit of a reduction in rural poverty may be highly mitigated and aggregate poverty may well increase.

The real exchange rate depreciation that often accompanies macroeconomic adjustment programs (at least in their initial stages) may also bring about indirect effects on poverty. For instance, it has been noted that a real depreciation can lead to an increase in the user cost of capital in the tradable sector, because capital 
goods (machinery and equipment) are often imported in developing countries (Lora and Olivera, 1998). This tends to lower investment in fixed capital and, as a result of complementarity, to reduce the demand for skilled workers. To the extent that skilled and unskilled labor are net substitutes (as the evidence suggests for many countries), the demand for unskilled workers may increase, raising employment and average income of the poor, thereby reducing the incidence of poverty. However, to the extent that the real depreciation is accompanied (or brought about) by a trade liberalization program that features a sharp reduction in tariffs, one may get the exact opposite results: the user cost of imported capital goods may fall significantly in net terms - thereby leading to an increase in the demand for skilled labor, a fall in unskilled employment, and an increase in poverty. Finally, if the real exchange rate depreciation is brought about by a nominal devaluation, and if the economy is a net importer of intermediate inputs (such as oil), the real depreciation will also represent a negative supply-side shock which may reduce the demand for labor (even in the tradables sector) - so much so that the net effect may be a contraction in output, an increase in unemployment and a higher incidence of poverty. The possibility that a nominal devaluation can be contractionary through adverse supply-side effects has indeed been noted in a number of analytical and empirical studies (see Agénor and Montiel, 1999, ch. 8).

\subsubsection{Macroeconomic Volatility}

A high degree of macroeconomic volatility is a well-documented feature of the economic environment in developing countries (see Agénor and Montiel, 1999, ch. 1). Such volatility results very often from external factors (such as sharp changes in a country's terms of trade or fluctuations in world interest rates, due to abrupt changes in market sentiment) but is also sometimes policy-induced, in part as a result of the absence of rules-based policymaking and the propensity to adopt 'stop-and-go' policies. In turn, macroeconomic volatility can affect the poor through the following channels:

- Investment and growth. Volatility tends to distort price signals and the expected rate of return for investors; in the presence of irreversibility effects (see Dixit and Pindyck, 1994), the decision to wait may lead to lower private investment and lower growth rates. Nonlinearities generated by capital market imperfections may also lead to significant effects of volatility on investment (Aizenman and Marion, 1999).

- Precautionary savings. The propensity to save for both rich and poor households may increase if macroeconomic volatility translates into higher income uncertainty or an increased probability of facing borrowing constraints in 'bad times' (as in Agénor and Aizenman, 2000). However, higher savings may also increase resources available for financial intermediaries to lend to potential investors, thereby stimulating growth; the net effect on poverty is thus a priori ambiguous. 
- Credit market effects. A higher degree of macroeconomic volatility may heighten the perceived risk of default by lenders, and either increase the incidence of credit rationing or lead to a higher risk premium and borrowing rates for private firms (see Agénor and Aizenman, 1998). This may have an adverse effect on labor demand and the poor.

- Distributional effect. This effect may itself result from changes in inflation (see below).

Several studies have recently focused on the impact of macroeconomic volatility on growth. Bleaney (1996), for instance, in a cross-section study covering the period 1980-90, found that macroeconomic instability (particularly when measured by the fiscal balance and the degree of volatility of the real exchange rate) has a significant negative effect on the rate of economic growth and possibly also a negative effect on investment. ${ }^{19}$ Rodrik (1998) obtained similar results for sub-Saharan Africa. Evidence for Latin America also suggests that macroeconomic volatility has tended to worsen income distribution and increase poverty in the region (Londoño and Székely, 1997). ${ }^{20}$ Overall, therefore, the foregoing discussion suggests that macroeconomic adjustment, to the extent that it results in greater macroeconomic stability, may well lead to higher growth rates and reduce the incidence of poverty.

\subsubsection{Distributional Effects}

As noted in the previous section, the impact of growth on poverty can be highly mitigated by changes in income distribution. In general, large differences may exist between countries rergarding the extent to which growth (even when it is distribution-neutral) will affect poverty. Under distribution-neutrality, the higher the extent of initial inequality, the lower the poor gain from growth - a smaller share of total income implies a smaller absolute gain from a given increase in total income. However, in practice growth is not always distribution neutral. Indeed, the evidence reviewed by Bruno, Ravallion, and Squire (1998) suggests that and that changes in distribution can indeed have a large impact on poverty. They estimate that, holding mean income constant, a 1 percentage point increase in the Gini index is typically associated with roughly a 4 percentage point increase in the proportion of the population living on less than $\$ 1$ a day. There is also a growing analytical literature suggesting that initial distribution matters to the extent and nature of subsequent growth (see, for instance, Galor and Zeira, 1993). This link can operate through credit market constraints, which limit the ability of the poor to invest in acquiring skills and may therefore tend to perpetuate poverty.

Another channel through which inequality may affect growth is through changes in macroeconomic volatility. Ramey and Ramey (1995) found that greater volatility of the growth rate tends to reduce the average rate of growth - an effect that may in part be due to its deterring effect on physical and human capital accumulation. More recently, Breen and Garcia-Penalosa (1999), using a cross-section of 80 developed and developing countries, found that income inequality is positively

(C) Blackwell Publishing Ltd. 2004 
correlated with aggregate volatility, measured by the standard deviation of the annual growth rate of output.

Several explanations have been put forward to account for the adverse impact that inequality may have on macroeconomic volatility and ultimately on growth. Alesina and Perotti (1996) argued that high inequality may lead to political instability, which may in turn results in high macroeconomic volatility and lower growth. Aghion et al. (1999, pp. 1628-30), by contrast, argued that there is a direct effect of inequality on macroeconomic fluctuations. Inequality in (initial) resources leads to inequality in access to investment opportunities across individuals in the presence of capital market imperfections - as a result, for instance, of collateral requirements. This can generate persistent and large cyclical fluctuations in credit and investment (as individuals increase borrowing during booms and reduce it during recessions) that are detrimental to growth because of unexploited opportunities to invest in high-yield projects.

An important question is, then, what accounts for changes in income distribution? Figure 4 displays the correlation between the Gini coefficient and real GDP per capita for the sample of developed and developing countries included in the study of Dollar and Kraay (2001). The figure suggests a 'clustering' pattern - higher-income developed countries, in general, tend to have lower inequality than developing countries. At the same time, within the group of developing countries, the relationship appears to be positive - a relationship that is consistent with the view that higher inequality is conducive to a higher aggregate propensity to save, higher rates of capital accumulation, and higher growth rates. However, recent formal econometric studies (such as Barro, 2000) have been unable to find a robust relation between per capita income and inequality. In particular, the hypothesis of a Kuznets curve, an inverted U-shape relation between income levels and inequality, appears to be fragile (see also Fields (2001) and Fishlow (1995)). There is stronger evidence that changes in income inequality are related to investment in human capital - and thus to borrowing constraints, as noted earlier. As argued by Londoño and Székely (1997, 2000), in particular, the worsening in income inequality observed in Latin America in recent years appears to have been the result of growing inequalities in educational opportunities and inadequate access to credit markets.

High and variable inflation may also explain large changes in the distribution of income and wealth; such effects may be of considerable importance in evaluating the costs and benefits of macroeconomic adjustment programs. In general, changes in income distribution are the result of two categories of factors: the allocation of assets (both real and financial) and their relative rates of return. Inflation affects income distribution through both channels. First, it affects the relative values of different assets and liabilities. By lowering the real value of both nominal assets and liabilities, unanticipated inflation, in particular, favors debtors and holders of real equity over lenders and owners of nominal assets. In the absence of indexation, it also affects negatively workers locked in long-term employment contracts. The net distributional effects will depend on access to hedging instruments (most notably the degree of contractual indexation), the incidence and length of contracts, and the distribution of nominal assets and liabilities across income groups. In developing

(C) Blackwell Publishing Ltd. 2004 


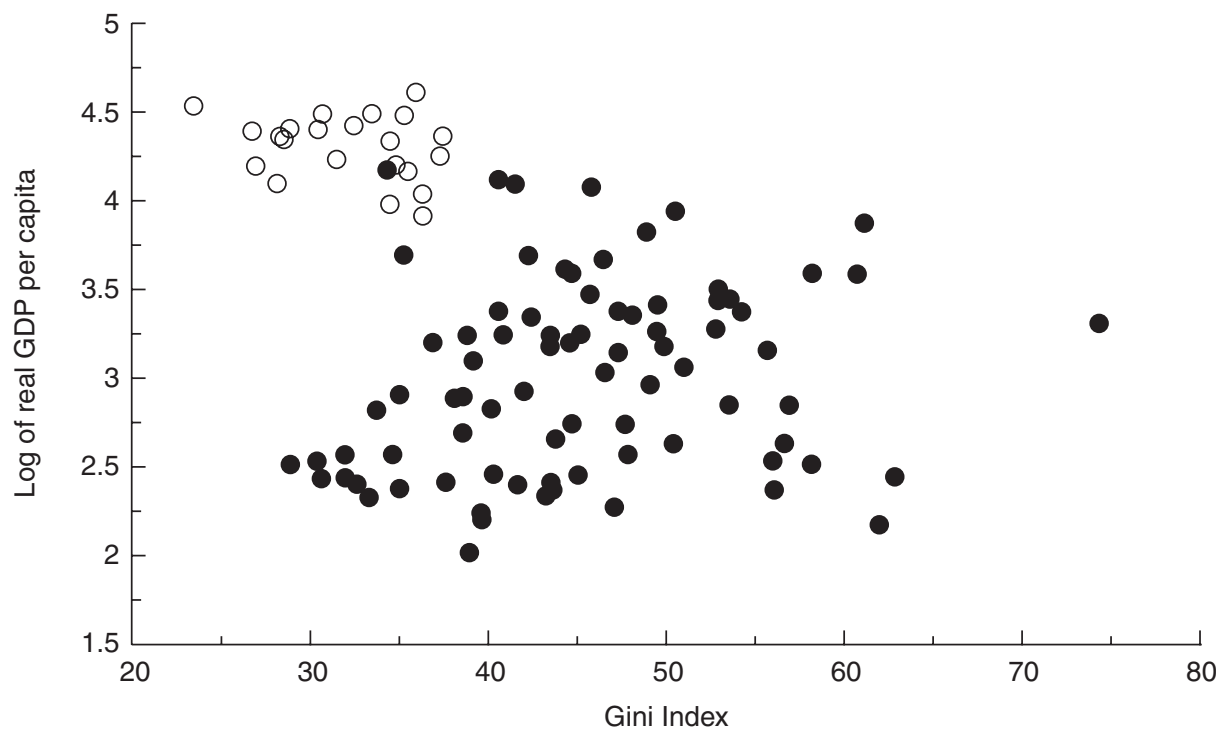

Figure 4. Gini Index and Per Capita Real GDP (annual averages, various periods).

Source: Dollar and Kraay (2001) and World Bank.

Note: The list of countries includes both industrial and developing countries (countries in transition are excluded from the Dollar-Kraay sample). The light-colored circles represent industrial countries.

countries with a relatively unsophisticated financial system, lower-income groups rarely hold significant nominal liabilities (such as mortgages), in contrast to middleincome groups. As a result, the poor may suffer from inflation through an erosion of their nominal assets (as noted earlier), whereas the middle class may benefit from an erosion of its nominal liabilities.

Second, inflation affects income distribution by altering relative returns on assets. If indexed assets and foreign-currency denominated assets are held principally by upper-income groups, whereas lower-income groups hold mainly domestic cash, then inflation (even if it is expected) will increase inequality, because the inflation tax (as noted earlier) will be borne by the poorer segments of society. Third, high inflation may also affect income distribution indirectly by lowering output and employment through a variety of channels, including distortions in relative price signals and their effects on allocative efficiency, as discussed earlier.

In sum, the foregoing discussion suggests that in principle inflation may either increase or reduce distributional inequalities; the direction of the net effect cannot be established a priori. Indeed, Figure 5, which displays the correlation between inequality (as measured by the Gini index) and inflation for the group of developed and developing countries included in the data compiled by Dollar and Kraay (2001), does not show any obvious association between the two variables - beyond the clustering pattern observed in Figure 4. However, several formal empirical studies

\footnotetext{
(C) Blackwell Publishing Ltd. 2004
} 


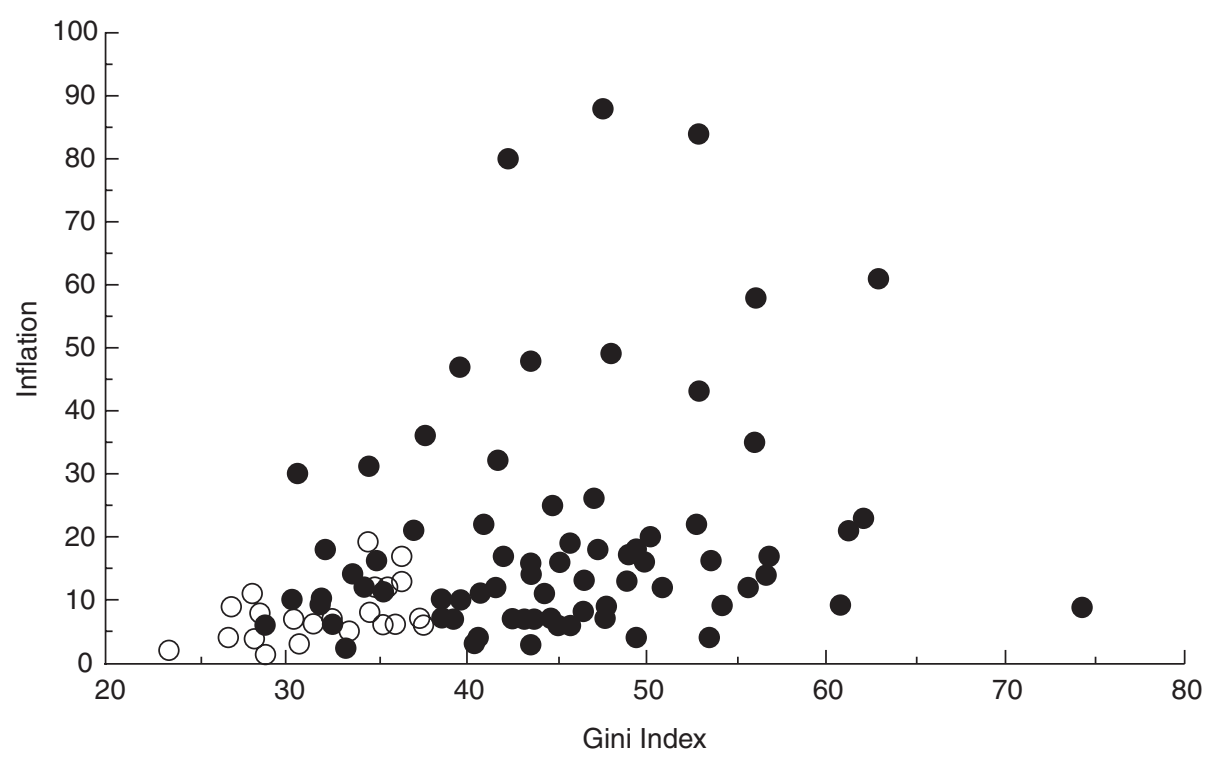

Figure 5. Gini Index and Inflation (annual averages, various periods). Source: Dollar and Kraay (2001) and World Bank.

Note: The list of countries includes both industrial and developing countries (countries in transition are excluded from the Dollar-Kraay sample). The light-colored circles represent industrial countries.

found that inflation tends indeed to increase inequality. Bulir (2001), in particular, found that the adverse effect of inflation on income distribution is highly significant at high inflation levels. In such conditions, macroeconomic adjustment, by lowering mean inflation and its variability, may well have a very significant effect on poverty, through a reduction in income inequality.

\subsection{Asymmetric Effects of Cycles and Crises}

A growing body of empirical evidence suggests that cyclical downturns and economic crises may have an asymmetric effect on poverty: recessions or sharp output contractions may increase poverty rates significantly, whereas expansions tend to have a more limited effect. To the extent that the austerity measures that are often at the core of macroeconomic adjustment programs lead to adverse, short-run movements in output, asymmetric effects may mitigate significantly the longer-run benefits of adjustment for the poor. It is thus important to understand the sources of asymmetry. Following Agénor (2001a), five main classes of explanations can be distinguished. The first dwells on parents' decisions regarding their children attending school; the second is based on asymmetric changes in expectations and confidence factors; the third relies on a 'credit crunch' at the firm level, with rationing induced by either adverse selection problems or negative 
shocks to net worth; the fourth emphasizes the impact of borrowing constraints on household consumption behavior; and the fifth dwells on 'labor hoarding' by firms facing high turnover costs for skilled labor.

\subsubsection{Schooling Effects}

A fall in real income during an economic downturn may have an irreversible impact on the human capital of the poor. Lustig (2000), for instance, argued that children in poor families (particularly the very poor ones) are sometimes taken out of school and put to work in response to large adverse shocks - in an attempt to mitigate the fall in the household's income - but are often not sent back to school when the 'good times' roll again. To the extent that negative shocks to income affect adversely the ability of the poor to enhance their stock of human capital, they will also hinder their ability to escape from poverty. Thus, large recessions create some sort of 'hysteresis' effect on poverty, in the sense of temporary negative shocks having persistent effects. However, the evidence supporting this view is mixed; for instance, Neri and Thomas (2000) found that in Brazil, children are not more likely to drop out of school in recessions than during expansions. At the same time, the evidence gathered by Gaviria (2001) for seven Latin American countries suggests that it is the lower middle-class households (rather than the poor households) that are more likely to cut back on human capital investments in response to adverse income shocks.

\subsubsection{Expectations and Confidence Factors}

Consumers and firms may be more pessimistic during recessions than they are optimistic during expansions, and immediate prospects may matter more during downturns than future prospects. If consumers and firms worry more about the overall economic outlook and the economy's likely direction in a downturn, a positive output shock - induced by, say, a relaxation of credit constraints or an increase in government spending - may have a smaller impact (and thus be less effective) on private spending decisions during recessions than during booms. In addition, if the perceived degree of uncertainty about future profitability rises during recessions, firms may be less willing to invest - even after a large positive shock to aggregate demand. The reason, of course, is the 'option value' associated with waiting for the uncertainty to dissipate (Dixit and Pindyck, 1994). If output and labor demand become less responsive to positive shocks during a recession, the initial increase in poverty induced by higher unemployment may be difficult to reverse.

\subsubsection{Adverse Selection, Net Worth, and the Credit Market}

Recessions may be accompanied by high or increasing interest rates because an economic slowdown may raise the risk of bankruptcy. This may lead banks to raise the premium that they charge over and above the cost of funds, as shown for

(C) Blackwell Publishing Ltd. 2004 
instance by Agénor and Aizenman (1998). An increase in the perceived risk of default may also lead to a tightening of credit constraints if lenders are unwilling to lend to riskier borrowers, as implied by adverse selection models of the credit market (see, for instance, Jaffee and Stiglitz, 1990). The tightening of credit constraints may magnify the impact of the initial recession on borrowing and spending, through both demand- and supply-side effects. The resulting fall in labor demand and thus the effect on poverty may also be compounded. If expansions are not characterized by an equivalent reduction in the perceived risk of default, adverse selection problems may impart an asymmetric bias to output shocks. ${ }^{21}$

A related argument that may explain a credit crunch in an economic downturn is based on net worth effects. A collapse in asset prices (e.g. real estate or equity prices) may lead to a sharp drop in the value of the collateral against which firms borrow. To the extent that firms (particularly small and medium-size ones) have limited alternatives to secure loans, banks may curtail credit because of the drop in value of assets that they can seize in case of default, possibly affecting smaller firms the most. A lower level of credit (or a higher risk premium) will, again, reduce output and employment, and eventually increase the incidence of poverty. An asymmetric effect may result from the fact that, after the crisis, economic uncertainty may remain high, expectations may remain pessimistic at least for a while, entailing as a result a slow recovery in asset prices.

\subsubsection{Borrowing Constraints and Household Consumption}

Credit constraints operating at the household level may also represent a source of asymmetry in the response of poverty to output shocks. If such constraints become binding during recessions - as a result of adverse selection, or net worth effects, because household wealth may be also adversely affected by sharp drops in asset prices - they may hamper the ability of households to smooth consumption. ${ }^{22}$ The available evidence suggests indeed that risk-sharing and consumption smoothing remain highly imperfect in developing countries. The poorest households are typically those least insured against shocks because of their inability to accumulate assets and because, as noted earlier, asymmetric information problems and high transactions costs may completely preclude access for them to private market insurance or credit mechanisms to smooth income fluctuations. As a result, consumption smoothing through borrowing and lending is simply not feasible. Poor households may then have no option but to engage in either sub-optimal labor allocation decisions (such as forcing children to quit school and work, as noted earlier), or to let consumption fluctuate as much as income - with possibly detrimental longer-run effects on productivity.

\subsubsection{The 'Labor Hoarding' Hypothesis}

Recessions may also worsen poverty through an asymmetric effect on employment and productivity (see Agénor, 1999, 2001a). In a downturn, unskilled workers 
(among which the poor tend to be concentrated) are often the first to lose their jobs as firms 'hoard' their skilled labor force because of the existence of relatively higher turnover costs (hiring, training and firing costs) associated with the use of that category of labor. The incentive to do so is greater the more transitory the shock is perceived to be. Firms are therefore off their (skilled) labor demand curve during recessions, and skilled workers' wages are higher than their marginal product. When the expansion phase comes, the priority for firms is often to recoup the productivity losses and foregone profit opportunities incurred during the downturn. If the degree of complementarity between skilled labor and physical capital is high (as the evidence suggests), they may increase fixed investment significantly and substitute away from unskilled labor. This, in turn, may produce a strong degree of persistence in unskilled unemployment and poverty over the course of the business cycle.

\subsection{The Role of the Labor Market}

The thrust of the foregoing discussion is that there are a variety of channels - with possibly offsetting (direct and indirect) effects - through which macroeconomic adjustment affects poverty. The importance of each of these channels will depend, of course, on the institutional and structural characteristics of individual economies. A key underlying theme of the discussion, however, is that the labor market is a crucial element in understanding the link between macroconomic adjustment and poverty. The poor often generate a significant share of their income from labor services. The way the labor market operates conditions the employment and wage outcomes of many specific policy decisions that are part of adjustment programs. There are, of course, more general reasons than poverty itself for focusing on the role of the labor market in the process of macroeconomic adjustment. Whether or not a devaluation leads to a reduction in the current account deficit, for instance, depends largely on the extent to which real wages are flexible downward. And labor market distortions may affect the productivity of all categories of workers, skilled and unskilled, thereby affecting the incomes of all types of households (rich and poor) and the economy's overall growth rate. Nevertheless, because of their precarious condition, the poor are likely to be particularly affected by labor market imperfections that hinder an efficient allocation of resources.

As noted earlier, for studies focusing on the role of short-term macroeconomic factors on poverty in developing countries, understanding the dynamics of the urban labor market is crucial. In this respect there are a number of important institutional characteristics of this market that need to be considered. ${ }^{23}$ In general, the urban labor market can be divided into a formal segment (which includes, on the demand side, large private enterprises and the public sector) and an informal segment, which is characterized by ease of entry, a high degree of wage flexibility, and the absence of enforcement of labor regulations. ${ }^{24}$ Because formal employment in many developing countries (in both Latin America and sub-Saharan Africa) has increased only slowly in recent decades, whereas urban migration has been extensive, informal urban employment has increased dramatically in size. In Kenya, for

(C) Blackwell Publishing Ltd. 2004 
instance, the share of the informal sector in employment outside agriculture is currently about 60\%. In Ghana, between 1980 and 1990, employment in the formal sector declined significantly, despite a substantial increase (by 50\%) of the nonagricultural labor force. Estimates by Canagarapajah and Mazumdar (1997, p. 45) suggest that much of the expansion in the labor force was absorbed by the informal sector, whose size increased from 36 to $45 \%$ of the total (agricultural and non-agricultural) labor force. In Bangladesh, $90 \%$ of the labor force is in the informal (nontraded) sector, mainly in rural areas. In Latin America, informal sector employment accounted for $57.4 \%$ of total employment in 1996, nearly 6 percentage points more than in 1990. For the region as a whole, the expansion in the number of informal sector jobs during the same period accounted for $80 \%$ of the net increase in employment (Lora and Olivera, 1998, p. 10). Figure 6 suggests that the size of the urban informal sector tends to be inversely related with the level and rate of growth of GDP per capita. There is also some evidence that the size of the informal sector is related to the tax burden; Figure 7 suggests indeed that both the share of overall tax revenue in GDP and the share of direct taxes in GDP are inversely related with the share of urban informal sector employment.

Empirical studies indicate that workers in the formal sector typically have higher levels of education than those employed in the informal sector. In part this is because formal sector firms use more advanced technologies, which require workers with higher levels of skills (and sometimes considerable on-the-job training) to be operated. Higher wages allow firms to reduce turnover costs for highly-skilled workers. A study of the manufacturing industry in Kenya, for instance, found a very significant effect of firm size on wages (Bigsten and Horton, 2001), even after controlling for (observable) labor quality differences and working conditions. In addition to reducing labor turnover, firms may be willing to pay more to enhance productivity, attract better workers, or maintain loyalty and morale, in line with various forms of efficiency wage theories (see Agénor, 1996, 2000). The evidence also suggests that the urban poor (who provide mostly unskilled labor) are disproportionately employed in the informal sector. In Chile, for instance, 30\% of employment in the total population was informal in 1994; it was 45\% amongst the poor (Anríquez et al., 1998). Estimates for sub-Saharan Africa are much higher. Thus, 'disguised' unemployment often characterizes the urban informal labor market. Other evidence indicates that open unemployment is also important in many developing countries, affecting both skilled and unskilled workers. This suggests that the extent of labor mobility between the formal and the informal sectors, although quite high, may not be perfect at least in the short run - thereby limiting the 'shock-absorbing', or countercyclical, role of the informal sector. The next section presents a macroeconomic model with a labor market structure that captures several of the characteristics highlighted above and analyzes the impact of fiscal adjustment on poverty.

\section{Macroeconomic Policy, the Urban Labor Market, and Poverty}

Dwelling on the above observations, this section presents a macroeconomic model of a small open developing economy that provides a useful framework for the

(C) Blackwell Publishing Ltd. 2004 


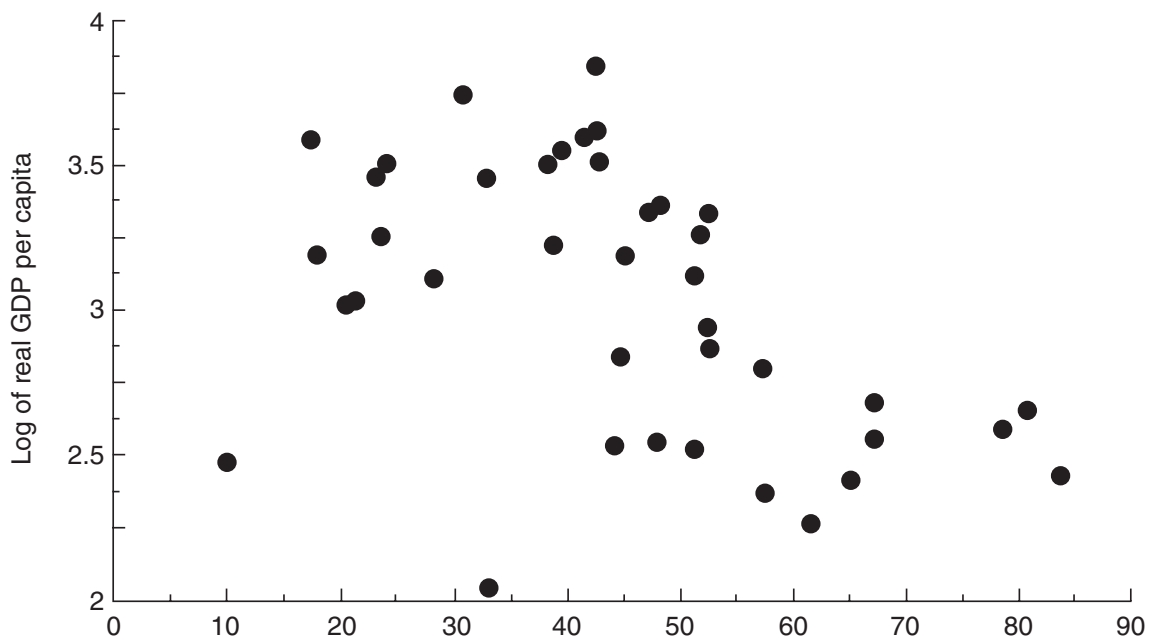

Urban informal sector employment (in percent of urban employment)

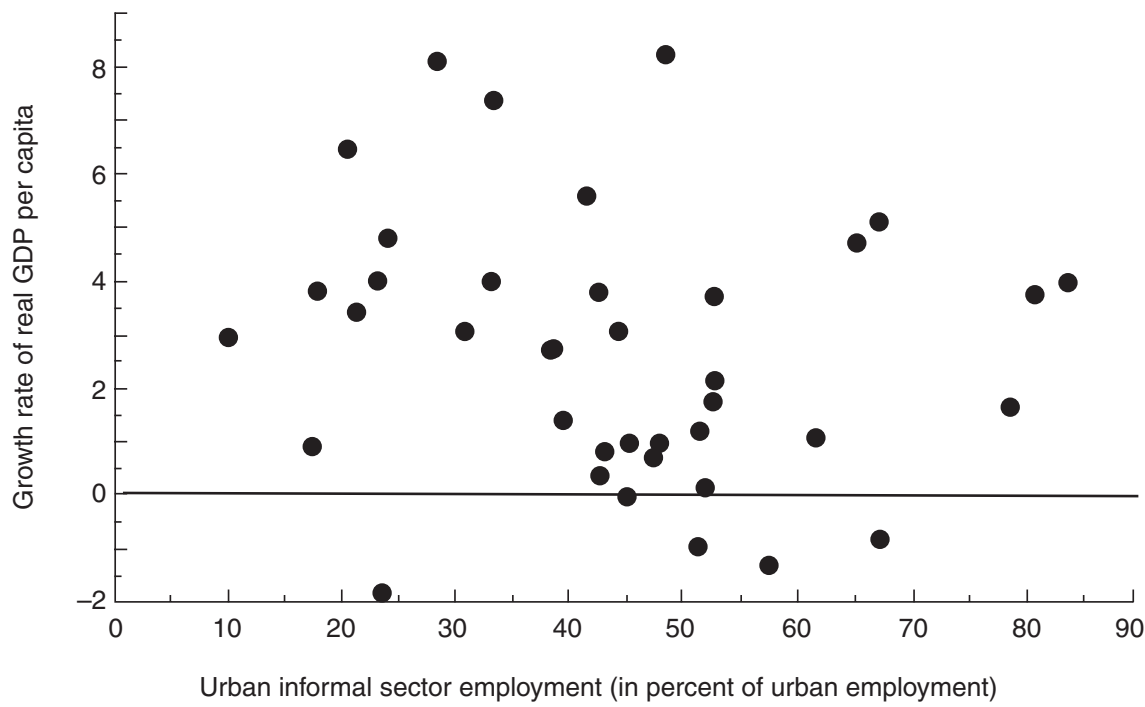

Figure 6. Developing Countries: Informal Sector and Per Capita Real GDP (averages).

Source: World Bank and International Labor Organization.

Note: The list of the countries is Argentina (1990-95), Bangladesh (1993), Benin (1992), Bolivia (1990-96), Botswana (1985, 1996), Brazil (1990-95), Cameroon (1993), Chile (1990-95, 1997), Colombia (1984,1986,1988,1990-95), Costa Rica (1990-95), Cote d'lvoire (1996), Ecuador (1990-97), Ethiopia (1996), Gambia (1992-93), Ghana (1997), Guatemala (1987, 1989), Honduras (1990-95), India (1993), Indonesia (1995), Iran (1996), Jamaica (1996), Kenya (1992-95), Madagascar (1995), Mali (1989, 1996), Mauritius (1992), Mexico (1990-96), Morocco (1988), Niger (1995), Pakistan (1992), Panama (1990-95), Paraguay (1990-96), Peru (1984, 1986-87, 1989-97), Philippines (1988, 1995), South Africa (1995), Sri Lanka (1985), Tanzania (1990-91, 1995), Thailand (1988, 1990-95), Tunisia (1981), Uganda (1993-94), Uruguay (1990-97), Venezuela (1990-97), Zambia (1993).

\footnotetext{
(C) Blackwell Publishing Ltd. 2004
} 


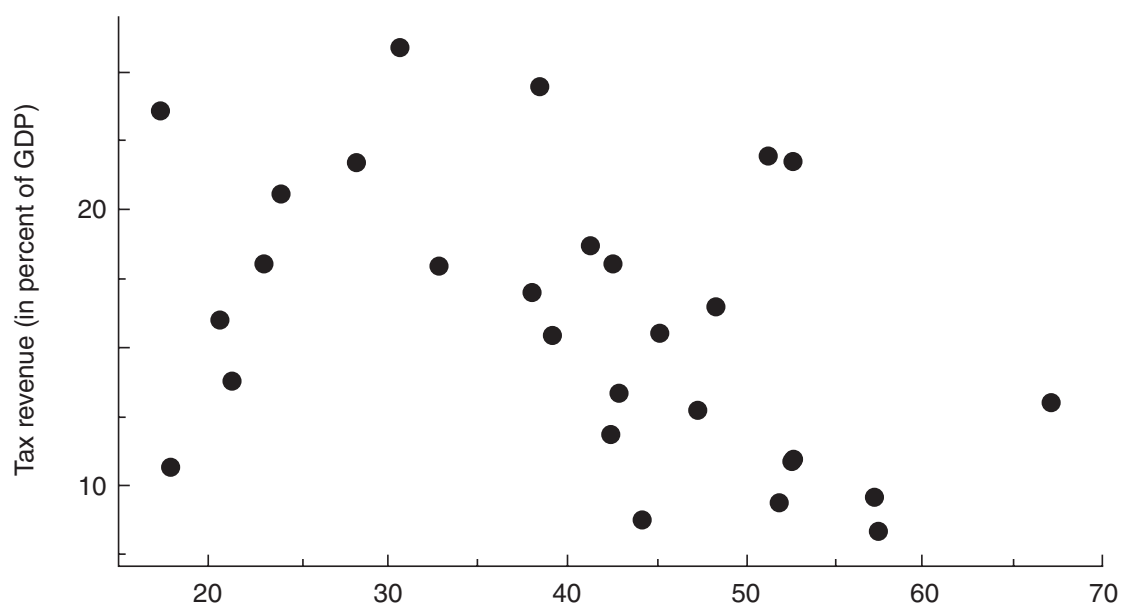

Urban informal sector employment (in percent of urban employment)

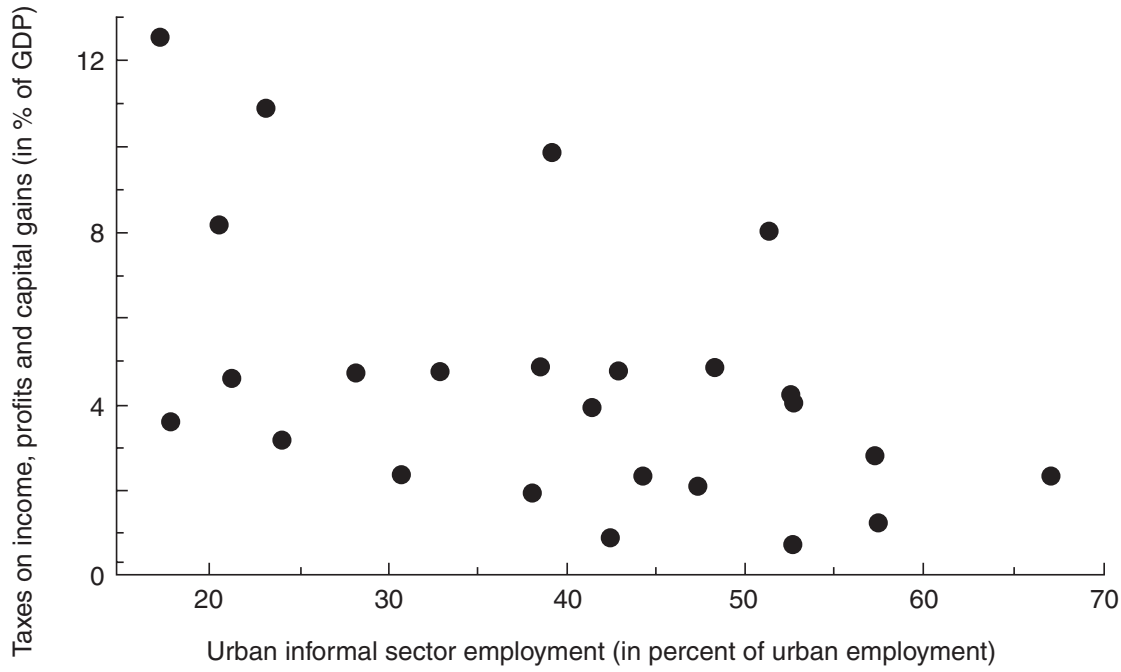

Figure 7. Developing Countries: Informal Sector Size and Tax Revenue (averages).

Source: World Bank and International Labor Organization.

Note: The list of the countries is Argentina (1990-95), Bolivia (1990-96), Botswana (1985, 1996), Brazil (1990-95), Cameroon (1993), Chile (1990-95, 1997), Colombia (1984, 1986, 1988, 1990-95), Costa Rica (1990-95), Cote d'lvoire (1996), Ecuador (1990-97), India (1993), Indonesia (1995), Iran (1996), Kenya (1992-95), Madagascar (1995), Mauritius (1992), Mexico (1990-96), Morocco (1988), Pakistan (1992), Panama (1990-95), Paraguay (1990-96), Peru (1984, 1986-87, 1989-97), Philippines (1988, 1995), South Africa (1995), Sri Lanka (1985), Thailand (1988, 1990-95), Tunisia (1981), Uruguay (1990-97), Venezuela (1990-97).

analysis of the role of the labor market in the transmission of macroeconomic policies to the poor. ${ }^{25}$ Three categories of agents are assumed to operate in the economy considered: firms, households (or workers), and the government. ${ }^{26}$ The 
nominal exchange rate is fixed. The economy consists of two major segments, the formal economy and the informal sector. The capital stock in each production sector is fixed within the time frame of the analysis. The labor force is also fixed and consists of skilled and unskilled workers; within each group, workers are identical.

\subsection{Basic Structure}

\subsubsection{The Formal Sector}

Production in the formal economy consists of an exportable good and requires both types of labor. For simplicity, total output of exportables is assumed to be sold abroad. ${ }^{27}$ The price of exportables is fixed on world markets; the demand for exportables is infinitely elastic at that price, and output is supply-determined. Setting the world price of exportables to unity implies that the domestic price of exports is equal to the nominal exchange rate, $E$.

Let $Y_{X}$ denote the production of exportables, $n_{S}$ and $n_{U}$ employment levels of skilled and unskilled labor (measured in natural units) in that sector, and $e$ the level of effort provided by a typical skilled worker. The level of effort provided by an unskilled worker is constant and normalized to unity for simplicity. Assuming a Cobb-Douglas production technology yields ${ }^{28}$

$$
Y_{X}=\left(e n_{S}\right)^{\alpha} n_{U}^{1-\alpha}, \quad 0<\alpha<1 .
$$

Generalizing the specification developed by Agénor and Aizenman (1999), the effort function is defined as

$$
e=1-\Lambda\left(\frac{\Omega}{\omega_{S}^{c}}\right)^{\gamma}, \quad 0<\Lambda<1, \gamma \geq 0
$$

where $\omega_{S}^{c}$ denotes the consumption wage for skilled workers in the exportables sector, and $\Omega$ the worker's reservation wage. Equation (2) indicates that an increase in skilled workers' consumption wage relative to their reservation wage raises the level of effort. Effort is also concave in $\omega_{S}^{c}$. If effort is independent of relative wages $(\gamma=0)$, or if the consumption wage is continuously equal to the reservation wage, $e=1-\Lambda .^{29}$

Whereas skilled workers determine the level of effort on the basis of the consumption wage that they face, producers set instead the product wage, $\omega_{S}$. Suppose that the consumer price index is a weighted, geometric average of the price of imported goods, $E$ - assuming that the foreign-currency price of these goods is normalized to unity - and the price of nontradables, $P_{N}$ :

$$
P=E^{1-\delta} P_{N}^{\delta}, 0<\delta<1
$$

where $\delta$ measures the share of home goods in total expenditure.

(C) Blackwell Publishing Ltd. 2004 
Let $z=E / P_{N}$ denote the relative price of imports in terms of nontradables; $z$ will be referred to in what follows as the real exchange rate. By definition, therefore, $P=z^{-\delta} E$, so that

$$
\omega_{S}^{c}=z^{\delta} \omega_{S}
$$

A binding minimum wage for unskilled workers is in place in the formal economy. For a given level of the minimum wage, firms in the formal sector determine employment levels and the product wage earned by skilled workers so as to maximize profits and minimize the cost of skilled labor in efficiency units. Formally, let $\omega_{m}$ be the real minimum wage (measured in terms of the price of exportables) earned by unskilled workers in the formal sector. Assuming that firms incur no hiring or firing costs, the firm's decision problem is thus

$$
\max _{n_{S}, n_{U}, \omega_{S}} \Pi_{X}=\left\{\left[1-\Lambda\left(\frac{\Omega}{z^{\delta} \omega_{S}}\right)^{\gamma}\right] n_{S}\right\}^{\alpha} n_{U}^{1-\alpha}-\omega_{S} n_{S}-\omega_{m} n_{U},
$$

with $z$ and $\omega_{m}$ taken as given.

The first-order conditions for this optimization problem are:

$$
\begin{gathered}
\alpha\left(\frac{n_{U}}{e n_{S}}\right)^{1-\alpha}\left[1-\Lambda\left(\frac{\Omega}{z^{\delta} \omega_{S}}\right)^{\gamma}\right]=\omega_{S}, \\
(1-\alpha)\left(\frac{n_{U}}{e n_{S}}\right)^{-\alpha}=\omega_{m}, \\
\alpha\left(\frac{n_{U}}{e n_{S}}\right)^{1-\alpha} n_{S}\left(\frac{\partial e}{\partial \omega_{S}}\right)=\alpha \gamma \Lambda\left(\frac{n_{U}}{e n_{S}}\right)^{1-\alpha}\left(\frac{n_{S}}{\omega_{S}}\right)\left(\frac{\Omega}{z^{\delta} \omega_{S}}\right)^{\gamma}=n_{S} .
\end{gathered}
$$

The first two conditions equate the real net marginal product of each category of labor to the relevant real wage. The third determines skilled workers' wage so as to ensure that the level of effort is optimal. It can be re-written as

$$
\alpha \gamma \Lambda\left(\frac{n_{U}}{e n_{S}}\right)^{1-\alpha}\left(\frac{\Omega}{z^{\delta} \omega_{S}}\right)^{\gamma}=\omega_{S},
$$

which can be equated with condition (5) to give

$$
(1+\gamma) \Lambda\left(\frac{\Omega}{z^{\delta} \omega_{S}}\right)^{\gamma}=1
$$

so that

$$
\omega_{S}=\frac{[(1+\gamma) \Lambda]^{1 / \gamma} \Omega}{z^{\delta}}=\theta(z, \Omega), \theta_{z}<0, \theta_{\Omega}>0 .
$$

Equation (8) indicates that the efficiency wage for skilled workers is negatively related to the real exchange rate and positively to the opportunity cost of effort. 
For a given level of the reservation wage, a depreciation of the real exchange rate induced by a fall in the price of nontradables increases the consumption wage and raises the level of effort - allowing firms to reduce the equilibrium product wage.

The demand functions for labor can be derived from the above equations as:

$$
n_{S}^{d}=n_{S}^{d}\left(\bar{\omega}_{S} ; \bar{\omega}_{m}\right), n_{U}^{d}=n_{U}^{d}\left(\bar{\omega}_{S} ; \bar{\omega}_{m}\right)
$$

These equations indicate that an increase in the product wage for either category of labor reduces the demand for both of them, as a result of gross complementarity.

Substituting these results in equation (1) and using (8) yields the supply function of exportables:

$$
Y_{X}^{s}=Y_{X}^{s}\left(\bar{\omega}_{S} ; \bar{\omega}_{m}\right)=Y_{X}^{s}\left(\stackrel{+}{z} ; \bar{\omega}_{m}\right)
$$

\subsubsection{The Informal Economy}

Firms in the informal economy produce a nontraded good, which requires only unskilled labor and is used only for final consumption. The price of this good is flexible, and adjusts to equilibrate supply and demand.

Technology for the production of the nontraded good in the informal sector is characterized by decreasing returns to labor:

$$
Y_{N}=n_{N}^{\eta}, \quad 0<\eta<1,
$$

where $Y_{N}$ denotes output of home goods, and $n_{N}$ the quantity of labor employed in the informal economy. Producers maximize profits given by $z^{-1} Y_{N}-\omega_{N} n_{N}$, where $\omega_{N}<\omega_{m}$ denotes the real wage in the informal sector, measured in terms of the price of exportables. ${ }^{30}$ Profit maximization yields the familiar equality between marginal revenue and marginal cost, $\omega_{N}=Y_{N}^{\prime} / z$, from which labor demand can be derived as

$$
n_{N}^{d}=\left(\frac{\omega_{N} z}{\eta}\right)^{1 /(\eta-1)}, \quad n_{N}^{d \prime}<0,
$$

where $\omega_{N} z$ measures the product wage in the informal sector. Substituting equation (12) in (11) yields the supply function of informal sector goods:

$$
Y_{N}^{s}=\left(\frac{\omega_{N} z}{\eta}\right)^{\eta /(\eta-1)}, \quad Y_{N}^{s \prime}<0 .
$$

\subsubsection{Households}

There are two categories of households in the economy: an 'upper-income' household, which consists of all workers (skilled and unskilled) employed in the formal economy, and a 'low-income' household, which consists of all workers employed

(C) Blackwell Publishing Ltd. 2004 
in the informal sector. ${ }^{31}$ The key difference between upper- and low-income households is that the former group pays income taxes, saves a non-zero fraction of its current disposable income, and accumulates wealth in the form of a tradable interest-bearing bond, whereas the latter group pays no taxes and spends all of its income. Both categories of households supply labor inelastically and consume, in addition to the nontraded good produced in the informal sector, an imported good which is imperfectly substitutable for the home good.

Consider first the upper-income household. Its income consists of total output of exportables, $Y_{X}^{s}$, and interest income on holdings of traded bonds, $i^{*} B^{*}$, where $i^{*}$ is the world interest rate (assumed constant) and $B^{*}$ the foreign-currency value of these holdings. ${ }^{32}$ Total consumption expenditure, $c_{R}$, depends positively on both disposable income and current wealth:

$$
c_{R}=\alpha\left(Y_{X}^{s}+i^{*} B^{*}-T\right)+v B^{*}, \quad 0<\alpha<1, v>0,
$$

where $T$ denotes lump-sum taxes (measured in terms of the price of exportables) paid by the upper-income household. ${ }^{33}$

If all savings are invested in interest-bearing assets, the flow of savings or the stock of foreign bonds held by the upper-income household evolves over time according to

that is, using (14):

$$
\dot{B}^{*}=Y_{X}^{s}+i^{*} B^{*}-T-c_{R}
$$

$$
\dot{B}^{*}=(1-\alpha)\left(Y_{X}^{s}+i^{*} B^{*}-T\right)-v B^{*} .
$$

The upper-income household consumes imported goods (in quantity $c_{R}^{I}$ ) as well as home goods (in quantity $c_{R}^{N}$ ). Assuming a Cobb-Douglas sub-utility function, the allocation of total consumption expenditure among these goods is given by

$$
c_{R}^{I}=(1-\delta) c_{R}, \quad c_{R}^{N}=\delta z c_{R}
$$

where $\delta$, as indicated earlier, measures the share of home goods in expenditure.

Resources of the low-income household (measured in terms of exportables) consist of income generated in the informal economy, $z^{-1} Y_{N}^{s}$. All income is spent on consumption, $c_{P}$ :

$$
c_{P}=z^{-1} Y_{N}^{s}
$$

Assuming for simplicity an allocation rule across consumption goods that is similar to the upper-income household's yields

$$
c_{P}^{I}=(1-\delta) c_{P}, \quad c_{P}^{N}=\delta z c_{P} .
$$




\subsubsection{The Market for Informal Sector Goods}

The equilibrium condition of the market for informal sector goods can be written as:

$$
Y_{N}^{S}=c_{R}^{N}+c_{P}^{N}
$$

Using equations (13), (16) and (18), this condition becomes

$$
Y_{N}^{s}\left(\omega_{N} z\right)=\delta z\left(c_{R}+c_{P}\right)
$$

which can be re-written as, using (17):

$$
Y_{N}^{s}\left(\omega_{N} z\right)=\frac{\delta}{1-\delta} z c_{R}
$$

\subsubsection{The Informal Labor Market}

The demand for labor in the informal sector is derived from profit maximization and is given by equation (12). Determining the supply of labor involves two steps. First, in line with the 'luxury unemployment' hypothesis, skilled workers who are unable to obtain a job in the formal sector are assumed to prefer to remain unemployed rather than seek employment in the informal economy. ${ }^{34}$ Second, the supply of unskilled workers in the formal sector, $n_{U}^{s}$, is assumed to change gradually over time as a function of wage differentials across sectors. Wage and employment prospects are formed on the basis of prevailing conditions in the labor market. Thus, denoting by $n_{U}^{p}$ the constant number of unskilled workers in the labor force, the supply of labor in the informal sector, $n_{U}^{p}-n_{U}^{s}$, is also given at any point in time. The equilibrium condition of the labor market in the informal economy can consequently be written as

$$
n_{U}^{p}-n_{U}^{s}=n_{N}^{d}\left(\omega_{N} z\right)
$$

With wages in the informal sector adjusting continuously to equilibrate supply and demand for labor, this equation yields: ${ }^{35}$

$$
\omega_{N}=\omega_{N}\left(\bar{z},{ }_{n_{U}^{s}}^{+}\right), \quad \partial \omega_{N} / \partial z=-1,
$$

which indicates that a depreciation of the real exchange rate has an exact offsetting effect on the market-clearing wage. The reason is that, with labor supply constant, labor demand cannot change - which in turn requires the product wage, $\omega_{N} z$, to remain constant. An increase in the number of workers seeking employment in the formal economy has a positive effect on the marketclearing wage. ${ }^{36}$ 
Migration flows are determined by expected income opportunities, along the lines of Harris and Todaro (1970). ${ }^{37}$ The expected wage in the formal economy is equal to the minimum wage weighted by the probability of being hired in the exportables sector. Assuming that hiring in that sector is random, this probability can be approximated by the ratio of currently employed workers to those seeking employment, $n_{U}^{d} / n_{U}^{s}$. The expected wage in the informal economy is simply the going wage, because there are no barriers to entry in that sector. Thus, the supply of unskilled workers in the formal sector evolves over time according to

$$
\dot{n}_{U}^{s}=\beta\left\{\frac{\omega_{m} n_{U}^{d}}{n_{U}^{s}}-\omega_{N}\right\}, \quad \beta>0,
$$

where $\beta$ denotes the speed of adjustment. Implicit in the above formulation is the assumption that workers employed in the informal sector do not engage in onthe-job search. As suggested by Agénor (1999), this assumption can be motivated by the existence of informational inefficiencies. The labor market in many developing countries is characterized by the absence of institutions capable of processing and providing in a timely manner relevant information on job opportunities to potential applicants - particularly those with low levels of qualifications. As a result, job search for unskilled workers in the formal sector often requires, literally speaking, waiting for employment offers at factory gates.

\subsubsection{Government}

The government consumes only imported goods and finances its expenditure through lump-sum taxes collected on the upper-income household: ${ }^{38}$

$$
T=g_{I}
$$

where $g_{I}$ denotes the foreign-currency value of government imports.

\subsection{Long-Run Equilibrium}

The dynamic structure of the model is derived in Appendix A. ${ }^{39}$ As shown there, the dynamics of the model can be formulated in terms of the size of the unskilled labor force seeking employment in the formal economy, $n_{U}^{s}$, and the upperincome household's holdings of traded bonds, $B^{*}$. A key feature of the model is that, as implied by equation (22), in the long run the unskilled wage ratio - the ratio of wages earned by unskilled workers in the formal and informal sectors must be equal to the inverse of the unskilled employment ratio in the formal economy:

$$
\omega_{m} / \tilde{\omega}_{N}=\tilde{n}_{U}^{s} / \tilde{n}_{U}^{d}
$$


This equation indicates that, as long as the minimum wage exceeds the informal sector wage (as required here to avoid a corner solution), unskilled unemployment will emerge in equilibrium. As shown in Appendix A, in addition to condition (24), in the steady state the current account must be in equilibrium. From the steady-state solutions of $B$ and $n_{U}^{s}$, the equilibrium values of the 'short-run' variables, the real exchange rate and the real wage in the informal economy, can be derived.

The steady-state equilibrium of the model is depicted in Figure 8 . The locus $B B$ gives the combinations of $B^{*}$ and $n_{U}^{s}$ for which bond holdings remain constant, whereas the locus $L L$ depicts the combinations of $B^{*}$ and $n_{U}^{s}$ for which the size of the unskilled labor force seeking employment in the formal sector does not change over time. Stability (as discussed in Appendix A) requires $L L$ to be steeper than $B B$. The steady-state equilibrium obtains at point $E$. If the economy's initial position is at, say, point $A$ - characterized by a negative differential between the expected wage in the formal and the informal sectors, and a current account deficit - the transition toward the steady state will be characterized by a fall in the size of the unskilled labor force seeking employment in the formal sector and a reduction in holdings of foreign bonds (the economy must dissave to finance the external imbalance). Beyond point $A^{\prime}$ (located on $L L$ ), the expected income differential turns positive, because the continuous inflow of workers in the informal sector that occurs during the first phase of adjustment puts downward pressure on wages there. The supply of unskilled labor to the formal economy therefore begins to increase. Holdings of foreign bonds continue to decline, however, until the steady-state position is reached at $E$.

A graphical illustration of the partial, long-run equilibrium of the labor market, adapted from Agénor (1999, 2002), is presented in Figure 9. Panel A depicts the demand functions for labor in the formal sector. The demand curve for skilled labor, $n_{S}^{d}$, is downward-sloping, because it is negatively related to $\omega_{S}$, the wage earned by skilled workers. Skilled unemployment is given in Panel A by the distance between the fixed supply of skilled labor, $n_{S}^{p}$, and the equilibrium point on the demand curve (point $G$ ). The demand curve for unskilled labor, $n_{U}^{d}$, is also downward-sloping because of gross complementarity between skilled and unskilled labor. Curve $\mathrm{HH}$ in Panel B depicts the relationship between the (long-run) supply of unskilled workers in the formal sector, $n_{U}^{s}$, given by equation (24), and employment of unskilled workers in the formal economy, $n_{U}^{d}$. It is derived by using the market-clearing condition (21) - taking $z$ as given - to eliminate $\omega_{N}$ in (24). $H H$ has a positive slope that is greater than unity, as implied by the assumption that $\omega_{m}>\omega_{N}$. The difference between point $B$ (located on the 45-degree line) and $B^{\prime}$ (located on $H H$ ) gives unskilled unemployment. Curve $V V$ is given by $n_{U}^{p}-n_{U}^{s}$; it is thus a linear transformation of $H H$. It determines the supply of labor (and thus actual employment) in the informal economy (point $\left.B^{\prime \prime}\right)$. Given the labor demand curve in the informal sector, $n_{N}^{d}$, the market-clearing wage is determined at point $C$ in Panel $C$. The positive relationship between the skilled workers' wage and the informal sectorwage - obtained by combining (8), (21), and (24) - is displayed as curve $W W$ in Panel D. Thus, unemployment of

\footnotetext{
(C) Blackwell Publishing Ltd. 2004
} 


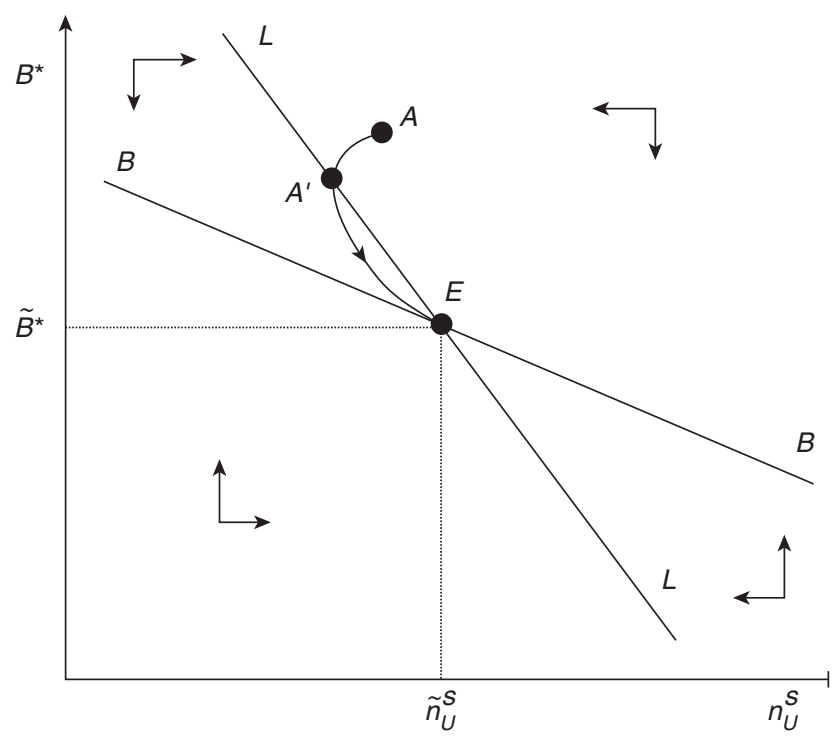

Figure 8. Steady-State Equilibrium.

both categories of labor - 'quasi-voluntary' unemployment of skilled workers and 'wait' unemployment of unskilled workers - prevails in equilibrium. ${ }^{40}$

\subsection{Fiscal Adjustment, Employment, and the Poor}

The model developed in the previous section can be used to analyze the labor market and poverty effects of a variety of macroeconomic policy shocks that have often been part of adjustment programs implemented in developing countries. For illustrative purposes, this paper limits itself to an analysis of the impact and steadystate effects of an increase in lump-sum taxes. This experiment also helps to illustrate the fact that fiscal austerity is not necessarily detrimental to the poor (even in the short run), once general equilibrium effects are properly accounted for.

\subsubsection{Steady-State Effects}

As shown in Figure 10, a rise in lump-sum taxes $T$ leads in the long run to a reduction in the stock of foreign bonds held by the upper-income household and an increase in the supply of unskilled labor in the formal sector. The new equilibrium is at $E^{\prime}$, located at the intersection of the new curves $B^{\prime} B^{\prime}$ and $L^{\prime} L^{\prime}$. Intuitively, the rise in $T$ has two effects. The first is that it dampens consumption of informal sector goods by the upper-income household. At the initial level of supply of these goods (that is, at the initial values of the real exchange rate and the product wage in that sector), the real exchange rate must depreciate. The second effect results from the fact that an increase in taxes also lowers private 


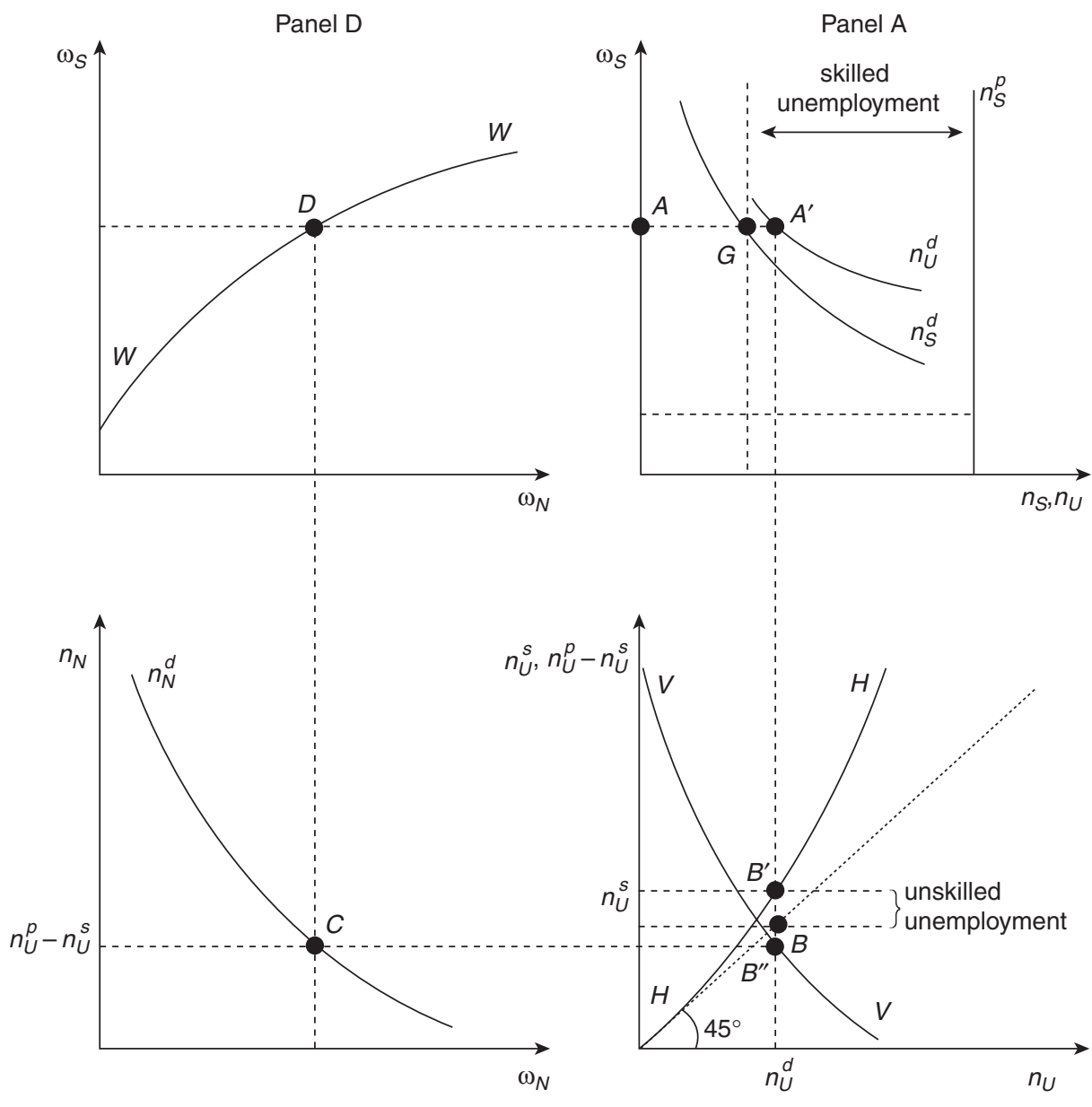

Panel C

Panel B

Figure 9. Labor Market Equilibrium.

Source: Agénor (2002).

spending on imports, whereas the real exchange rate depreciation stimulates exports. Both effects tend to create a current account surplus, at the initial level of the stock of foreign bonds held by the upper-income household. But for the current account to be in equilibrium in the long-run interest receipts on foreign bonds must fall to offset the improvement in the trade balance. And because the world interest rate does not change, this can happen only through a reduction in the stock of foreign bonds held by the rich.

The depreciation of the real exchange rate lowers skilled workers' efficiency wage in the formal sector, thereby raising the demand for both categories of 


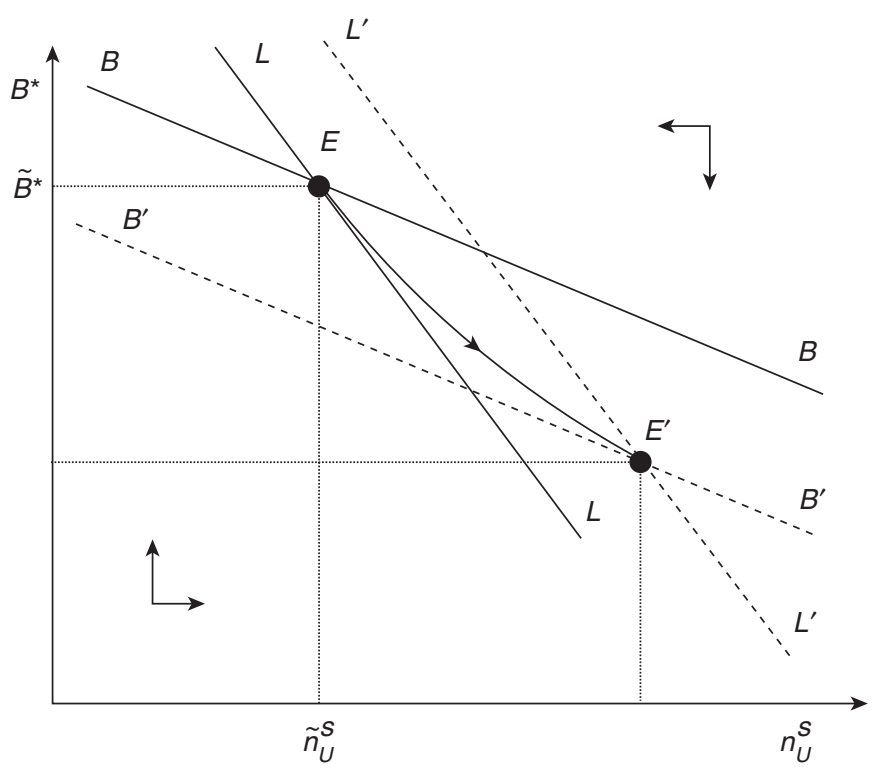

Figure 10. Increase in Lump-Sum Taxes.

labor. The increase in labor demand raises the probability of employment in the formal economy and thus expected income there. This tends to increase the supply of unskilled labor in the formal economy. Because the demand for skilled labor rises, the long-run effect of the shock is a reduction in the unemployment rate of skilled workers. Whether unemployment of unskilled workers rises or falls would seem to be a priori ambiguous; both the supply of, and the demand for, unskilled labor rise in the formal economy. As shown in Appendix A, however, it can be established that demand rises by more than supply in relative terms; the net outcome is thus a reduction in the rate of unemployment of unskilled labor in the urban formal sector. The fall in labor supply in the informal sector puts upward pressure on the market-clearing wage $\tilde{\omega}_{N}$ - thereby outweighing the negative effect of the real depreciation. ${ }^{41}$ The product wage there $\left(\tilde{\omega}_{N} \tilde{z}\right)$ unambiguously rises, which brings about the required reduction in labor demand. Thus, informal sector wages move in the same direction as output in the formal economy, whereas output and employment move in opposite directions in both sectors.

\subsubsection{Transitional Dynamics}

The transitional dynamics associated with the increase in taxes are also illustrated in Figure 10. The impact effects operate in the same direction as the long-run effects described earlier: a reduction in consumption of domestic and imported goods by the upper-income household, a real depreciation, a fall in skilled workers' wages, and an increase in the demand for both categories of workers. The rise 
in labor demand raises the probability of employment (and thus expected income) in the formal economy. The effect of the real depreciation on the product wage in the informal economy is now completely offset by a reduction in the real wage there; as a result, the differential between expected wages in the formal and informal sectors unambiguously rises - thereby raising on impact the flow of labor in the formal economy $\left(\dot{n}_{U}^{s}(0)>0\right)$. The reason why the initial movements in $z$ and $\omega_{N}$ exactly offset each other is that $n_{U}^{s}$ cannot change on impact. As a result, the product wage in the informal sector, $z \omega_{N}$, cannot change either, as can be inferred from equation (20). Thus, output and employment in the informal sector remain also constant on impact.

Although output of exportables rises as a result of the fall in skilled workers' wage, the net effect of the increase in taxes is a reduction in income and savings by the upper-income household, and thus a decumulation in holdings of foreign bonds $\left(\dot{B}_{0}^{*}<0\right)$. Over time, the adjustment process leads the economy monotonically from point $E$ to point $E^{\prime}$, where the current account is in equilibrium, the flow of savings is again zero, and expected wages between the formal and informal sectors are equal.

What happens to poverty rates during the adjustment process? Suppose that the legal minimum wage is used as the official poverty line, and that average income in the informal sector, $Y_{N}^{s} / n_{N}^{d}$, is less than $\omega_{m}$ at all times (given (11) and (12), this implies that $\left.\omega_{N} z / \eta<\omega_{m}\right)$. Suppose also that the unemployed earn an (imputed) income from own production that is less than $\omega_{m}$. The headcount index measure of poverty, $I_{H}$, can thus be defined as the number of workers employed in the informal sector, plus unemployed workers in the formal economy (skilled and unskilled), divided by the size of the labor force, $n$ :

$$
I_{H}=\frac{1}{n}\left\{n_{N}^{d}+\left(n_{S}^{p}-n_{S}^{d}\right)+\left(n_{U}^{s}-n_{U}^{d}\right)\right\},
$$

or equivalently, given that $n=n_{S}^{p}+n_{U}^{s}+n_{N}^{d}$ :

$$
I_{H}=1-\left(\frac{n_{S}^{d}+n_{U}^{d}}{n}\right) .
$$

On impact, as indicated earlier, the supply of unskilled labor in the formal economy remains constant, and employment in the informal sector does not change, because the product wage there remains constant. Thus, poverty falls as a result of the increase in the demand for both skilled and unskilled labor in the exportables sector. This is also the case in the long run. The analysis therefore helps to illustrate an important point that was alluded to earlier in less formal terms: fiscal austerity does not necessarily have an adverse effect on the poor, neither in the short or the long run. The reason is that the poverty effects of macroeconomic policies in a typical developing-country context operate through complex channels involving changes in aggregate demand and supply in the formal and informal sectors, as well as changes in relative prices and wages. Once these general equilibrium effects are accounted for, as was done here,

(C) Blackwell Publishing Ltd. 2004 
macroeconomic adjustment may well benefit the poor by stimulating employment - even while exerting downward pressure on wages.

\section{Empirical Evidence}

The thrust of the foregoing discussion is that it is usually difficult to draw clear-cut theoretical conclusions regarding the overall effect of macroeconomic variables on poverty, as a result of conflicting effects - operating either simultaneously or at different moments in time. Empirical studies are thus important to assess whether net effects are positive or negative. This section begins by reviewing some recent studies. It then presents some new econometric results for a cross-section of countries.

\subsection{Factual, Econometric, and Simulation Studies}

Existing studies analyzing the effect of macroeconomic factors on poverty consist of three main types: factual, econometric, and macro-simulation studies. Some of the factual studies focusing on Latin America have suggested, for instance, that the poverty impact of expenditure policies adopted in the context of stabilization (and structural adjustment) programs during the 1980s has often been negative. ${ }^{42}$ Another factual study that attempts to assess the effect of macroeconomic adjustment on poverty in sub-Saharan Africa is by Demery and Squire (1996). They use the macroeconomic policy index developed by the World Bank to do so. ${ }^{43}$ They found that improvements in macroeconomic management (as captured by changes in the policy index) are associated with a decline in the incidence of poverty. More specifically, Demery and Squire find that for the six African countries that they consider - Côte d'Ivoire, Ethiopia, Ghana, Kenya, Nigeria, and Tanzania - poverty fell in countries that improved their macroeconomic policy regime and deteriorated in the one case (Côte d'Ivoire) in which it did not. ${ }^{44}$ A depreciation of the real exchange rate was a key factor in the macroeconomic adjustment process; it also affected favorably rural incomes, benefitting the poor both directly and indirectly. In general, however, factual empirical studies aimed at assessing the link between macroeconomic adjustment programs and poverty face an important hurdle, namely, the fact that they typically do not consider 'counterfactual' scenarios. Too often the process of adjustment is blamed for the increase (or reduction) in poverty, without considering what would have happened in the absence of adjustment.

Among the econometric studies, Cardoso et al. (1995) and Amadeo and Neri (1997) have found that inflation and unemployment have an adverse effect on poverty in Brazil. Amadeo and Neri (1997), in particular, found that although inflation implies lower per capita income for all deciles of the distribution of income in Brazil, its effect on per capita earnings is lower for the upper-income households. Put differently, inflation has a larger effect on earnings of the poor than on average per capita income. The use of time-series data in a single-country context is an important avenue of future research in the analysis of the role of 
macroeconomic factors in the determination of poverty rates. Romer and Romer (1998), for instance, used time-series technique to investigate the short- and longrun effects of monetary policy on poverty and found that these effects go in opposite directions. Their evidence for the United States shows that a cyclical boom (and lower unemployment) created by an expansionary monetary policy is associated with improved conditions for the poor in the short run. Their crosssection evidence from a large sample of countries, however, shows that low inflation and stable aggregate demand growth are associated with lower poverty in the long run. Both the short- and long-run relationships are quantitatively large, statistically significant, and robust. But because the cyclical effects of monetary policy are inherently temporary, they concluded that monetary policy that aims at low inflation and stable aggregate demand is the most likely to permanently improve conditions for the poor. Agénor (2001a) used a vector autoregression approach to analyze the extent to which output shocks have an asymmetric effect on the poor in Brazil, while being simultaneously controlling for changes in the minimum wage and unemployment. This type of study should be further developed to include (vector) error-correction models, so as to distinguish, among the determinants of poverty, between long-run factors (such as the degree of inequality and the level of public expenditure on education and health) and short-term macroeconomic factors.

Some other studies have used simulation techniques to examine the effect of macroeconomic policy shocks on poverty. In particular, several recent papers focusing on sub-Saharan Africa have used computable general equilibrium (CGE) models for this purpose. Subramanian (1996), for instance, evaluated the impact of government policies (as well as external shocks) on poverty in Cameroon. Sarris (1996) examined the effects of various macroeconomic policy shocks (a $20 \%$ devaluation, an increase in public investment spending financed by a corresponding reduction in public current expenditure, and a reduction in public sector employment) in a CGE model for Tanzania. All shocks in his study resulted in short-term declines in real income for the rich and the poor alike. However, losses for the non-poor were significantly higher than the losses incurred by the poor (rural and urban), reflecting the losses in implicit rents. In the longer term, with output growth rates increasing and inflation falling, income gains were significant for both the poor and middle-income households. Other studies include Bourguignon et al. (1991) and Lofgren (2001).

A limitation of many existing CGE models, however, is that the treatment of the labor market, and more specifically wage formation mechanisms, often do not capture the complex intersectoral relationships that are observed in practice. The structure of the labor market has a major impact on the transmission of macroeconomic shocks and adjustment policies to economic activity, employment, and relative prices; but applied policy models have often captured only a narrow set of its features - such as an economy-wide rigid minimum wage (see for instance Maechler and Roland-Host, 1995). As illustrated in the analytical model presented earlier, for instance, feedback effects between formal and informal sector wages play a critical role in the transmission process of macroeconomic shocks in

(C) Blackwell Publishing Ltd. 2004 
a context in which efficiency considerations (or turnover costs) matter in the determination of formal sector wages. Existing models have paid insufficient attention to the macroeconomic implications of alternative sources of labor market segmentation, differences in wage formation across various labor categories, inter-sectoral wage rigidity (as opposed to aggregate wage rigidity), and feedback effects between relative prices and wage decisions by price-setting firms. All of these features have important implications for understanding the impact of policy and exogenous shocks on poverty. Labor market segmentation, in particular, tends to restrict labor mobility and can be associated with persistent wage differentials, as noted earlier; these, in turn, may prevent the reallocation of resources necessary to cope with external and policy-induced shocks. Again, because the poor in many developing countries generate a significant fraction of their income from labor services, accounting explicitly for the complexity of the labor market is crucial for understanding the impact of pretty much any type of shock on poverty in the short and medium run.

A detailed treatment of the labor market is a key feature of the Integrated Macroeconomic Model for Poverty Reduction (IMMPA) developed by Agénor, Izquierdo and Fofack (2002) and Agénor, Fernandes, and Haddad (2002). Another characteristic of IMMPA is that it accounts explicitly for the channels through which various types of public investment outlays affect the economy. Economists and policymakers have long recognized that different forms of public investment can have different effects on output and employment, but the channels through which alternative forms of public spending operate have seldom been incorporated explicitly in applied macroeconomic models used for development policy analysis. In IMMPA, investment in infrastructure (or, rather, the stock of public capital in infrastructure) affects directly the level of production in the private sector - and thus the marginal productivity of primary factors employed in that sector - whereas public investment in education has a direct impact on the decision to acquire skills. This effect operates in addition, of course, to movements in relative wages across skill categories and the initial level of individual wealth, which acts as a constraining factor in the presence of credit constraints. IMMPA also allows an analysis of the poverty and distributional effects of policy and exogenous shocks in two ways: first by calculating a set of indicators (for income distribution) based directly on the simulation results of the macro component; second, by linking these simulation results to a household expenditure survey. There are various country applications under way, most notably for Brazil, Cameroon, Morocco, and Senegal. Many fruitful lessons on the impact of adjustment on the poor are likely to emerge from them. ${ }^{45}$

\subsection{Cross-Country Econometric Evidence}

This section presents, in a cross-country empirical framework, some preliminary results on the relationship between macroeconomic factors and poverty in developing countries. ${ }^{46}$ The macroeconomic variables examined include several of the variables discussed earlier: public expenditure, inflation, income levels and output

(C) Blackwell Publishing Ltd. 2004 
growth, and the real exchange rate. In addition, several structural variables are also considered. The estimation method is a OLS with fixed effects. As discussed in Appendix B, the sample is relatively small (19 countries, and at most 52 observations).

Specifically, the dependent variable is the poverty rate $(P O V)$, measured by the headcount index for the population as a whole. The 'basic' set of explanatory variables used in the regressions are defined as follows (see Appendix B for more precise definitions): ${ }^{47}$

- INFL is the inflation rate in consumer prices;

- ILLITY is the youth illiteracy rate in percent of the adult population, which aims to capture the level of education of the labor force;

- LHOSPITAL is the log of hospital beds per 1,000 persons, which measures overall health conditions;

- GDPPC is GDP per capita at PPP exchange rates, which captures the level of economic development;

- REALGR is the annual growth rate of GDP per capita, measured at PPP exchange rates, which can be viewed as either a proxy for the rate of return on investment, or as a measure of cyclical movements in output;

- REALEX is the annual rate of change of the real effective exchange rate (defined such that an increase is a depreciation);

- URBAN is the relative share of the urban population in proportion to total population;

- $C T O T$ is the rate of change of the terms of trade;

- VREALXL and VINFL are measures of macroeconomic volatility, which consist of rolling standard deviations of the real exchange rate and inflation;

- $O P E N$ is the ratio of the sum of imports and exports of goods and services in percent of GDP, and aims to capture the degree of commercial openness.

The previous discussion suggests that inflation should have a positive effect on poverty. An increase in the illiteracy rate is expected to be positively correlated with poverty, whereas an improvement in health indicators should be inversely related to poverty. Both the level of GDP per capita and its rate of growth are expected to be negatively correlated with the poverty rate. The effect of a real exchange rate depreciation is in general ambiguous; it is likely to lead to a reduction in poverty if it benefits small farmers in the tradable sector, as is the case in many low-income developing countries. A higher rate of urbanization also has in general an ambiguous effect on aggregate poverty; to the extent that ruralto-urban migration translates into greater access to public services in urban areas, it may lower poverty; but to the extent that inflows of workers in the urban sector lead to an excess supply of labor in the informal sector and lower wages there, it may increase poverty. An improvement in the terms of trade may reduce poverty if it represents an increase in the relative price of agricultural commodities (thereby benefiting small farmers in rural areas) or a fall in the price of imported consumption goods (benefiting mostly households in urban areas). An increase in

(C) Blackwell Publishing Ltd. 2004 
macroeconomic volatility (associated with output shocks, inflation, or fluctuations in the real exchange rate) is expected to increase poverty, possibly through its adverse effect on growth, as discussed earlier. Finally, the degree of openness has a priori an ambiguous effect on poverty. To the extent that trade openness increases exposure to external shocks, or if greater access to imported capital goods leads firms to substitute away from unskilled labor in the production process, it may increase poverty; but to the extent that it gives greater access to foreign intermediate inputs and foreign technology, it may end up benefitting the poor.

Table 1 summarizes some of the basic empirical results. They indicate that changes in the terms of trade, the urbanization ratio, the illiteracy rate and the volatility of inflation do not have a statistically significant impact on poverty. ${ }^{48}$ By contrast, inflation has in general a significant, adverse effect on poverty, in line with the earlier results reported by Agénor (1999) and Easterly and Fischer (2001). A greater degree of openness tends to reduce poverty significantly, as is the case for the number of hospital beds (which has the correct sign and is significant in several regressions). Both the level of real GDP per capita and its growth rate have the expected negative sign and are highly significant in almost all regressions. The rate of depreciation of the real exchange rate has a strong, negative effect on poverty, which is consistent with the view that improvements in the relative price of tradables benefit farmers producing exportables in the agricultural sector. The volatility of the real exchange rate is also highly significant, indicating that macroeconomic instability has an adverse impact on poverty possibly through its effect on income distribution, as noted earlier. Finally, the fixed effects (which are not reported here to save space) are all statistically significant, suggesting that country-specific factors are important in determining the behavior of poverty rates.

Table 2 extends the analysis in Table 1 to account for the possibility of asymmetric output shocks in both the level of real GDP per capita and its growth rate. Specifically, observations on the level and growth rate of GDP per capita are split into two sub-samples. In both cases, two dummy variables, DUMMYPOS and $D U M M Y N E G$, are created; for the level of GDP per capita, the first is equal to 1 times GDPPC when GDPPC at period $t$ is higher than GDPPC at time $t-1$ (and 0 otherwise), and the second is equal to 1 times GDPPC when GDPPC at period $t$ is lower than GDPPC at time $t-1$. For the growth rate, the first is equal to 1 times $R E A L G R$ when $R E A L G R$ is positive (and 0 otherwise), and the second equal to 1 times the absolute value of $R E A L G R$ when $R E A L G R$ is negative (and 0 otherwise). The results show first that all the variables that were significant in Table 1 remain so; in particular, real exchange rate depreciations, a higher degree of openness, and better health conditions tend to lower poverty, whereas inflation and macroeconomic volatility tend to increase it. The results also show that there is no evidence of asymmetric effect of the level of GDP per capita on poverty: both variables have coefficients that are significant and statistically indistinguishable. By contrast, positive growth rates of output have no statistically significant effect on poverty, whereas higher negative growth rates affect significantly and

(C) Blackwell Publishing Ltd. 2004 


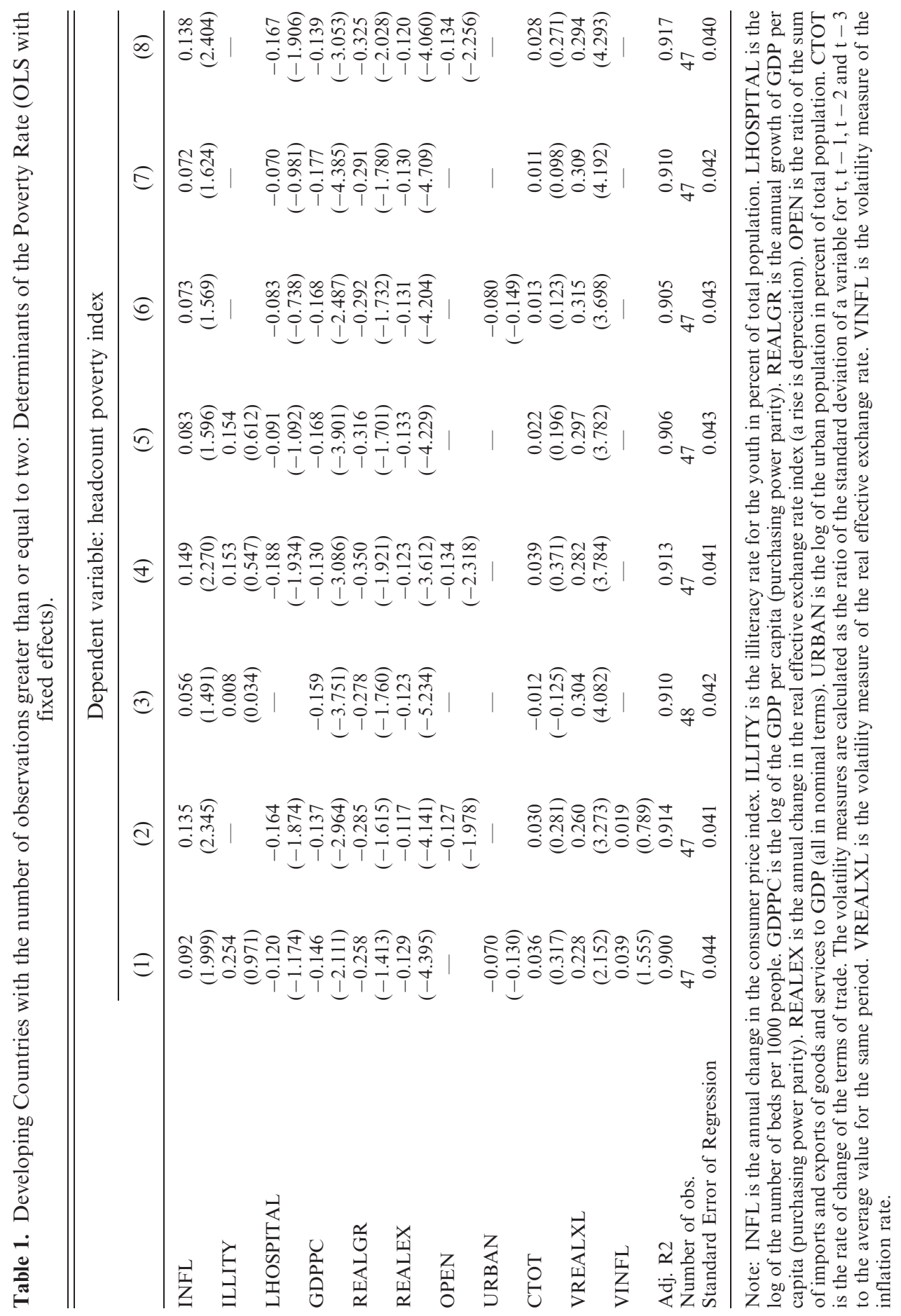


Table 2. Developing Countries with the number of observations greater than or equal to two: Asymmetric Effects on Poverty (OLS with fixed effects).

\begin{tabular}{|c|c|c|c|c|c|}
\hline & \multicolumn{5}{|c|}{ Dependent variable: headcount poverty index } \\
\hline & (1) & (2) & (3) & (4) & (5) \\
\hline INFL & $\begin{array}{c}0.089 \\
(1.821)\end{array}$ & $\begin{array}{c}0.136 \\
(2.771)\end{array}$ & $\begin{array}{c}0.074 \\
(2.062)\end{array}$ & $\begin{array}{c}0.143 \\
(2.670)\end{array}$ & $\begin{array}{c}0.077 \\
(1.956)\end{array}$ \\
\hline ILLITY & $\begin{array}{c}0.162 \\
(0.582)\end{array}$ & - & - & $\begin{array}{c}0.119 \\
(0.351)\end{array}$ & - \\
\hline LHOSPITAL & $\begin{array}{l}-0.127 \\
(-1.239)\end{array}$ & $\begin{array}{l}-0.179 \\
(-2.261)\end{array}$ & $\begin{array}{l}-0.079 \\
(-1.214)\end{array}$ & $\begin{array}{l}-0.190 \\
(-2.373)\end{array}$ & $\begin{array}{l}-0.128 \\
(-1.303)\end{array}$ \\
\hline NEGREALGR & $\begin{array}{c}0.804 \\
(1.735)\end{array}$ & $\begin{array}{c}1.115 \\
(2.941)\end{array}$ & $\begin{array}{c}0.879 \\
(2.071)\end{array}$ & $\begin{array}{c}1.040 \\
(2.157)\end{array}$ & $\begin{array}{c}0.909 \\
(2.192)\end{array}$ \\
\hline POSREALGR & $\begin{array}{c}0.118 \\
(0.487)\end{array}$ & $\begin{array}{c}0.048 \\
(0.202)\end{array}$ & $\begin{array}{c}0.135 \\
(0.603)\end{array}$ & $\begin{array}{c}0.031 \\
(0.123)\end{array}$ & $\begin{array}{c}0.153 \\
(0.679)\end{array}$ \\
\hline NEGGDPPC & $\begin{array}{l}-0.108 \\
(-1.562)\end{array}$ & $\begin{array}{l}-0.113 \\
(-2.637)\end{array}$ & $\begin{array}{l}-0.141 \\
(-3.847)\end{array}$ & $\begin{array}{l}-0.105 \\
(-2.535)\end{array}$ & $\begin{array}{l}-0.105 \\
(-1.518)\end{array}$ \\
\hline POSGDPPC & $\begin{array}{l}-0.112 \\
(-1.673)\end{array}$ & $\begin{array}{l}-0.114 \\
(-2.695)\end{array}$ & $\begin{array}{l}-0.144 \\
(-4.049)\end{array}$ & $\begin{array}{l}-0.107 \\
(-2.681)\end{array}$ & $\begin{array}{l}-0.109 \\
(-1.619)\end{array}$ \\
\hline REALEX & $\begin{array}{l}-0.186 \\
(-5.630)\end{array}$ & $\begin{array}{l}-0.177 \\
(-5.983)\end{array}$ & $\begin{array}{l}-0.183 \\
(-5.934)\end{array}$ & $\begin{array}{l}-0.176 \\
(-5.914)\end{array}$ & $\begin{array}{l}-0.190 \\
(-5.552)\end{array}$ \\
\hline OPEN & - & $\begin{array}{l}-0.130 \\
(-2.044)\end{array}$ & - & $\begin{array}{l}-0.126 \\
(-1.826)\end{array}$ & $\begin{array}{c}-0.297 \\
(-0.626)\end{array}$ \\
\hline URBAN & $\begin{array}{l}-0.175 \\
(-0.360)\end{array}$ & - & - & - & - \\
\hline СТOT & $\begin{array}{l}-0.024 \\
(-0.251)\end{array}$ & $\begin{array}{c}-0.034 \\
(-0.352)\end{array}$ & $\begin{array}{l}-0.045 \\
(-0.448)\end{array}$ & $\begin{array}{l}-0.022 \\
(-0.229)\end{array}$ & $\begin{array}{c}-0.038 \\
(-0.402)\end{array}$ \\
\hline VREALXL & $\begin{array}{c}0.292 \\
(3.489)\end{array}$ & $\begin{array}{c}0.256 \\
(3.763)\end{array}$ & $\begin{array}{c}0.284 \\
(4.183)\end{array}$ & $\begin{array}{c}0.253 \\
(3.662)\end{array}$ & $\begin{array}{c}0.307 \\
(3.839)\end{array}$ \\
\hline Adj. R2 & 0.903 & 0.917 & 0.911 & 0.913 & 0.907 \\
\hline Number of obs. & 47 & 47 & 47 & 47 & 47 \\
\hline $\begin{array}{l}\text { Standard Error } \\
\text { of Regression }\end{array}$ & 0.044 & 0.040 & 0.042 & 0.041 & 0.043 \\
\hline
\end{tabular}

Note: INFL is the annual change in the consumer price index. ILLITY is the log of the illiteracy rate for the youth in percent of total population. LHOSPITAL is the log of the number of beds per 1000 people. NEGREALGR (POSREALGR) is equal to 1 times the absolute value of REALGR (growth rate of GDP per capita) when REALGR is negative (positive), zero otherwise. NEGGDPPC (POSGDPPC) is equal to 1 times GDPPC (level of GDP per capita) when GDPPC is lower (higher) than GDPPC $(-1)$, zero otherwise. REALEX is the annual change in the real effective exchange rate index (a rise is depreciation). OPEN is the ratio of the sum of imports and exports of goods and services to GDP (all in nominal terms). URBAN is the urban population in percent of total population. CTOT is the rate of change of the terms of trade. The volatility measures are calculated as the ratio of the standard deviation of a variable for $t, t-1, t-2$ and $t-3$ to the average value for the same period. VREALXL is the volatility measure of the real effective exchange rate.

adversely the poor. A similar result was obtained by De Janvry and Sadoulet (2000) using a more parsimonious regression framework. This asymmetric effect is very important. As noted by De Janvry and Sadoulet (2000, p. 284), to the extent that the growth-poverty correlation results mainly from episodes 
of negative growth rates and increases in poverty, it may lead to erroneous predictions about the potential of growth-oriented policies to reduce poverty.

Table 3 extends the results of Tables 1 and 2 in two directions. First, a measure of inequality, the Gini coefficient, taken from Dollar and Kraay (2001) is added to the regression. Bourguignon (2000) recently emphasized the importance of including a measure of inequality as a regressor in estimating the impact of growth and standards of living on poverty; the previous discussion also suggests the same approach. Second, to test for possible endogeneity problems with respect to income, both the level and the rate of growth of GDP per capita are lagged by one period. The first set of regressions, (1) to (7), show that, by and large, the previous results remain unchanged. An improvement in health conditions or a higher rate of real exchange rate depreciation tend to lower poverty, whereas inflation, macroeconomic volatility and now a higher degree of inequality, tend to increase it. Furthermore, as indicated in regressions (8) to (10), there is again evidence in favor of an asymmetric effect on the rate of growth (not the level) of income per capita when the rate of depreciation of the real exchange rate is dropped out of the regression. ${ }^{49}$ In line with the previous characterization of the sources of asymmetry, a possible explanation of the latter result is that the rate of growth acts as a proxy for the rate of return on capital. In recessions (or periods of negative growth), the perceived degree of uncertainty about future profitability increases, which leads firms to adopt a 'wait and see' attitude, as a result of irreversibility effects.

The foregoing results are only suggestive. Data limitations and the relatively small number of degrees of freedom limit their reliability. In addition, there are serious measurement problems. For instance, measured poverty rates in the sample may be overstated to the extent that the estimate of income reflects only market or market-related activities. Expanding the database used here would allow expanding the range of variables to be tested - such as for instance the impact of inequality in assets, as opposed to income. In the same vein, it would be useful to develop a measure of financial openness (in addition to the trade openness index used in the regressions) in order to assess the impact of international financial integration on poverty. Finally, it should be noted that the role of the labor market is only implicit (or indirect) in the regression framework used above. Extending the analysis to account explicitly for labor market variables (such as changes in unskilled unemployment, which are only imperfectly correlated with changes in output growth) would allow a more precise assessment of its importance in the transmission of macroeconomic policy to poverty.

\section{Summary and Conclusions}

The purpose of this paper has been to examine analytically and empirically the various channels through which stabilization policies affect poverty in developing countries, with a particular emphasis on the role of the labor market. Macroeconomic policies must, of course, be evaluated in terms of their macroeconomic objectives; in addition, however, it is important to understand their impact on

\footnotetext{
(C) Blackwell Publishing Ltd. 2004
} 


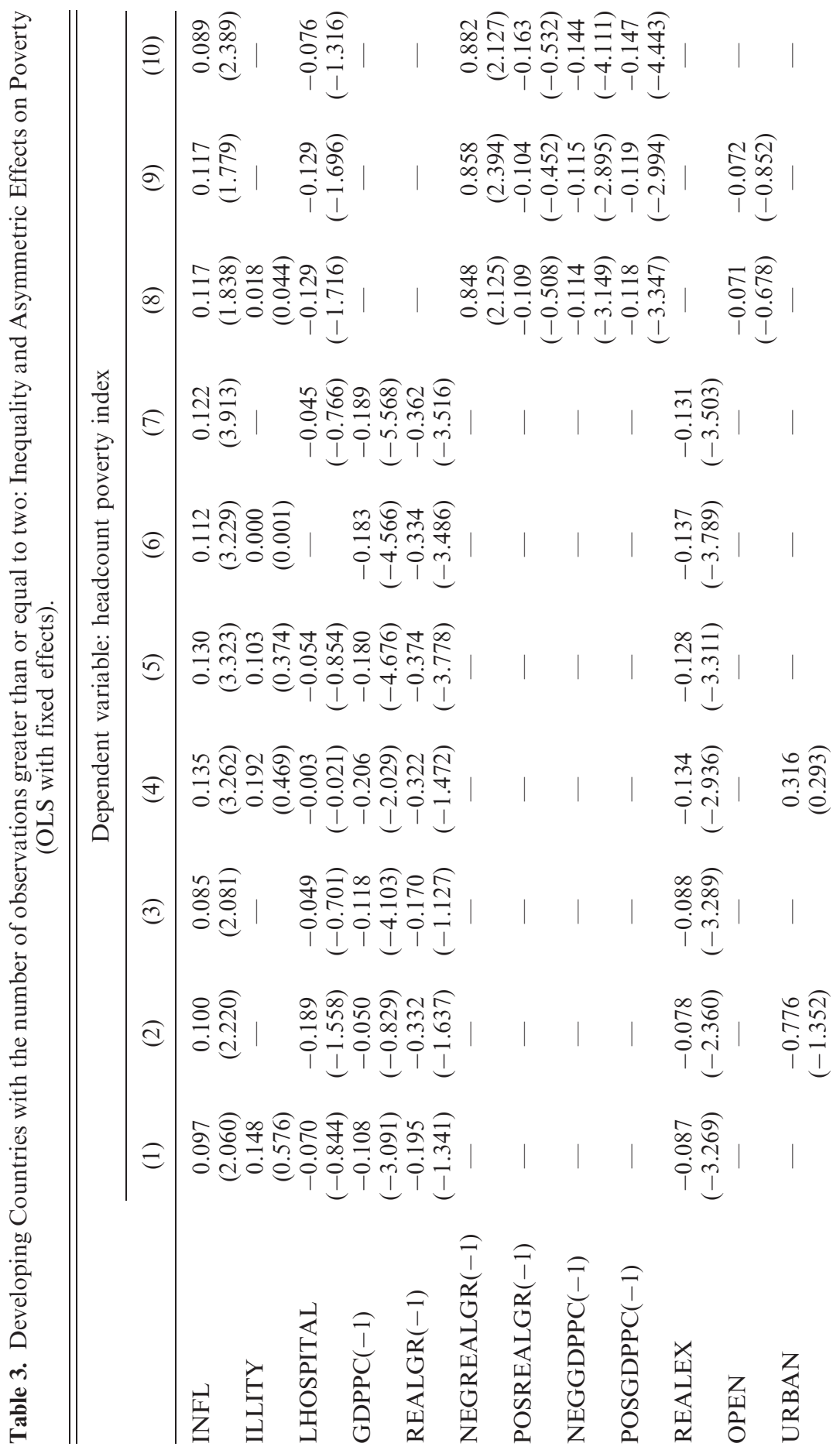




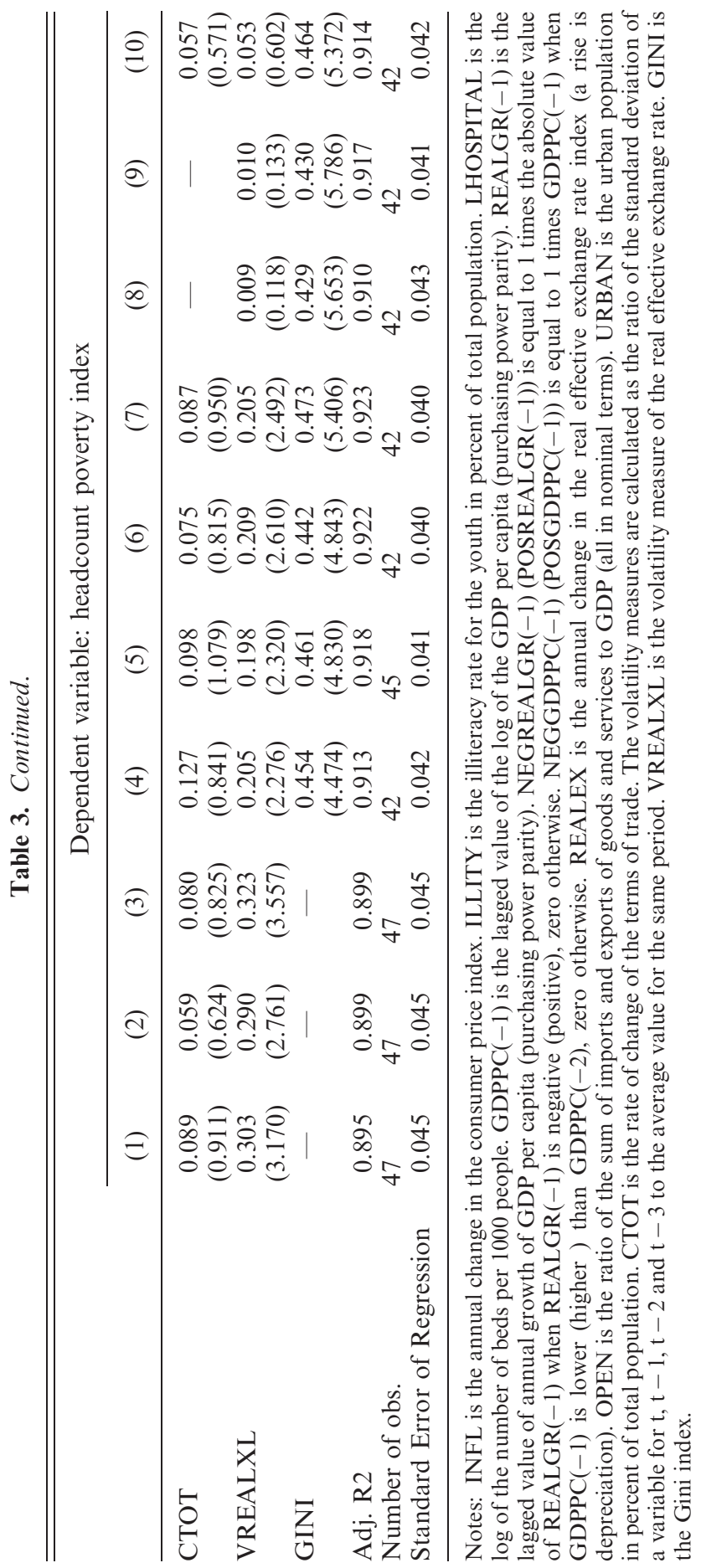


poverty. This issue has been the subject of renewed interest in studies of economic adjustment in developing countries.

The first part of the paper provided a brief review of the recent evidence on poverty, and highlighted the large differences between and within regions of the developing world. The second part provided an analytical overview of the various channels through which macroeconomic policies affect the poor. It was argued, in particular, that a reduction in government expenditure on transfers and subsidies (measured either as a proportion of GDP or as a share of total spending) does not necessarily hurt the poor if it is accompanied by a better targeting of benefits. It was also pointed out that there are several factors suggesting that macroeconomic adjustment might benefit the poor. If the tradable goods sector is labor intensive, the poor will gain from the relative price shifts associated with a real exchange rate depreciation. At the same time, a reduction in (policy-induced) macroeconomic volatility is likely to lead to an increase in savings and investment rates, and thus be conducive to growth. However, these predictions must be qualified because various other factors may mitigate the positive impact of adjustment on the poor. Structural characteristics (such as the extent of price and wage flexibility, the degree of inter-sectoral mobility of the labor force, the extent to which the poor consume tradable goods, and the extent to which they are directly affected by cuts in public expenditure) vary considerably across countries and make it necessary to address these issues on a case by case basis.

The third part presented an analytical framework that captures some of the main features of the urban labor market in developing countries - a large informal sector, efficiency wages and minimum wage legislation in the formal economy, and imperfect mobility of the unskilled labor force across sectors. Both skilled and unskilled unemployment were shown to emerge in equilibrium, despite wage flexibility in the informal sector. Skilled unemployment emerges because the opportunity cost of leisure is low and/or the reservation wage is higher than the going wage in the informal sector, whereas unskilled unemployment results from 'wait' or 'queuing' considerations in the tradition of Harris and Todaro (1970). The model was used to study the macroeconomic effects of fiscal adjustment, namely, an increase in lump-sum taxes on upper-income households. The analysis suggested that in the long run this policy leads to a real exchange rate depreciation and lower unemployment of both categories of labor. It also lowers poverty (with the poor defined as unemployed workers and those employed in the informal sector). This experiment serves to illustrate the importance of accounting for general equilibrium effects in assessing the impact of macroeconomic adjustment on poverty; whereas the direct, partial equilibrium effect of higher taxes is to reduce aggregate demand and employment, the changes in relative prices and wages that result from the initial response of the economy translate into economy-wide movements in labor demand and output. These movements may operate in opposite direction to the initial effects and may end up being beneficial for the poor.

The fourth part provided a brief overview of some of the existing empirical studies focusing on the effect of macroeconomic adjustment on poverty, and presented some cross-country econometric results focusing on some of the factors

(C) Blackwell Publishing Ltd. 2004 
identified in the previous sections - such as the level of activity, the rate of output growth, changes in the real exchange rate, inflation, and macroeconomic volatility - as well as structural factors (degree of urbanization, health conditions, illiteracy rate, and the degree of income inequality). Although the results should be treated with some caution given the relatively short sample size and some serious measurement problems, they suggest that higher levels and growth rates of per capita income, higher rates of real exchange rate depreciation, better health conditions, and a greater degree of commercial openness lower poverty, whereas inflation, greater income inequality, and macroeconomic instability (as measured by the degree of volatility of the real exchange rate) tend to increase it. In addition, real output growth per capita was found to have an asymmetric effect on poverty: positive growth rates are not statistically significant, whereas higher negative growth rates are significant and tend to raise poverty. Ignoring this asymmetric effect may lead to an overestimation of the potential of growthoriented policies to reduce poverty.

The analysis presented in this paper can be extended in various directions. The cross-country econometric results presented here could be extended to explicitly account for the structure of the labor market and the role of labor market variables in the transmission of macroeconomic policy shocks. For instance, labor market regulations, by reducing the demand for unskilled labor in the formal economy, may raise poverty in both the short and the long term. Fallon and Lucas (1993), for instance, found that in Zimbabwe job security regulations (including restrictions on firms' ability to dismiss redundant workers) reduced employment by increasing adjustment costs and reducing efficiency. More generally, the evidence appears to suggest that countries that have managed to reduce poverty dramatically have all typically been able to increase the demand for unskilled labor rapidly. To the extent that labor market imperfections hamper the creation of (unskilled) jobs, there may be a close link between reforms aimed at improving the functioning of the labor market and policies aimed at alleviating poverty.

Another potentially fruitful area of research is related to the degree of intersectoral mobility of the labor force. As noted earlier, the speed of labor reallocation plays a crucial role in understanding the impact of shocks on poverty and the labor market. However, the available evidence on the degree of labor mobility across sectors in developing countries remains rather scant. In practice, labor mobility depends on a variety of factors, such as employment protection regulations (most notably administrative restrictions on hiring, plant closure and layoffs of permanent labor, and the generosity of severance payments) and other microeconomic considerations, such as proximity and family ties. Fallon and Riveros (1989) took the fact that wage differentials during the early 1980s tended to widen in favor of expanding (tradable) sectors in the urban sector in Argentina, Chile, Colombia, Mexico, and Uruguay as indicating less than perfect labor mobility. However, differences in the pattern of wage formation across industries may well explain such movements. There is a need therefore to extend research on these issues. ${ }^{50}$ One 
possibility would be to follow the approach of Dickens and Lang (1985), which relies on switching regression analysis. ${ }^{51}$ The Dickens-Lang method could be used to test for the presence of non-economic barriers to formal sector employment. Their approach consists in postulating a mechanism for the allocation of workers between the formal and informal sectors in the absence of rationing, based on workers' employment choices. Assuming that workers have perfect information and would behave so as to maximize utility over their lifetime, they would choose formal sector employment if the net present value of their income stream in the formal economy exceeded that of the informal sector. This proposition can be tested by a series of constraints on the switching regression. ${ }^{52}$ But in practice, assessing the degree of mobility between the formal and informal sectors in developing countries is difficult because data on migration flows between these sectors are generally not available. However, the model developed earlier suggests that the ratio of formal sector wages (for workers with low qualifications) to informal sector wages can be a useful empirical proxy. The model, in fact, suggests an ambiguous effect of the wage differential on poverty, to the extent that the poor are viewed as consisting of all those employed in the informal sector as well as the openly unemployed in the formal economy. ${ }^{53} \mathrm{~A}$ fall in the formalinformal wage ratio, for instance, increases the flow of unskilled workers to the informal sector. To the extent that these workers were previously unemployed, poverty would not change; but to the extent that they were initially employed in the formal sector, poverty would naturally increase. Similarly, a rise in the wage ratio would have an ambiguous effect on poverty because those workers who move to the formal sector to seek a job there may well be unsuccessful and end up joining the ranks of the unemployed. What the foregoing discussion suggests, nevertheless, is that adding the formal-informal sector wage ratio as an independent variable in the type of poverty regressions presented earlier may be one way to capture, with appropriate auxiliary assumptions, the effect of intersectoral labor flows on poverty rates.

\section{Acknowledgements}

This paper dwells on some of my recent work on labor market segmentation and asymmetric shocks. I am grateful to the Editor and two anonymous referees for helpful comments on a previous version, and to Nihal Bayraktar for excellent research assistance. The views expressed in this paper do not necessarily reflect those of the Bank.

\section{Notes}

1. Efficiency wage considerations have been much discussed in the recent literature on labor markets in developing countries (see Agénor, 1996). Rationales include better nutrition, incentive and morale factors, adverse selection, turnover costs, and shirking costs. As discussed below, such considerations are particularly important for large, capital-intensive firms, which typically operate in the urban formal economy.

(C) Blackwell Publishing Ltd. 2004 
2. See Fields (2001) and Ravallion (1994) for a discussion of this measure of poverty, as well as the poverty gap (discussed later), and their limitations.

3. It should also be kept in mind that measures of rural and urban poverty rates - such as those discussed by Sahn et al. - are often made on the basis of expenditure data that are not properly deflated across regions, owing to the lack of appropriate regional deflators. Accounting for the difference between the cost of living between urban and rural areas is nevertheless crucial for poverty assessment, in part because prices are typically higher in urban areas. Mazumdar (1993) for instance estimated that in Kenya in the late 1980s, the nominal income differential between rural and urban areas was as high as $4: 1$, and the cost of living in urban areas was $60 \%$ higher. Without price indices (and thus relative weights) that account for consumption patterns in both areas, the difference between the incidence of poverty in rural and urban areas may be overstated.

4. In Ghana, for instance, the sharp reduction in the rural poverty rate between 1987 and 1992 (from $42 \%$ to $34 \%$ ) was the result of a significant increase in the income generated by the poor from non-farm self-employment. According to Canagarapajah and Mazumdar, (1997, p. 44), the share of such income in total household income increased from $19.5 \%$ in $1987-88$ to $25.7 \%$ in $1991-92$. At the same time, the share of income generated from farm self-employment fell during the same period from $60.4 \%$ to $53 \%$.

5. Of course, a reduction in the share of marketed agricultural output would also lower cash income and possibly force a reduction in the consumption of non-agricultural goods by the rural poor.

6. By contrast, for the period between 1987 and 1992, Anríquez et al. (1998) found that in Chile up to $80 \%$ of the reduction of poverty was due to growth, with the rest due to changes in income distribution.

7. Government spending on transfers and subsidies also have an indirect effect on aggregate demand, and changes in public sector prices may have an indirect impact on other prices in the economy, as discussed later.

8. Large reductions in subsidies have often been seen as a reflection of the lack of political influence of the poor and pressures exerted by more powerful interest groups.

9. Conversely, of course, social spending may fall more than proportionately during periods of fiscal consolidation. Ravallion (2000) documents the experience of Argentina during the 1980s and 1990s, when pro-poor social spending fell significantly.

10. Indirect effects through portfolio shifts (and capital gains and losses) are typically limited because the poor hold their assets mostly in the form of noninterest-bearing money or bank deposits. There may, of course, be a large effect on relative poverty (that is, income distribution) through this channel, to the extent that upper-income groups hold more diversified portfolios of assets.

11. These effects may be exacerbated in the presence of wage and price stickiness (resulting, for instance, from the prevalence of nominal wage contracts and rigid mark-up pricing rules), which imply larger quantity adjustments in the short run.

12. The evidence favoring the Ricardian Equivalence proposition in developing countries is, however, rather weak; see Agénor (2000, ch. 1)).

13. However, this effect is probably relatively small in practice, due to the fact the savings rates of the poor are low to begin with.

14. For Latin America, see in particular Cardoso (1992) and Morley (1995).

15. However, it is possible (at least in principle) that the inflation tax revenue serves to finance a higher level of public expenditure that benefits the poor directly - thereby mitigating the adverse, partial equilibrium effect of the tax on welfare. 
16. See Temple (2000 b) for a comprehensive and critical review of the recent literature on inflation and growth, focusing particularly on methodological issues, including the possibility of nonlinearities.

17. Note, however, that there are possible offsetting effects. For instance, a high and variable inflation rate can lead to higher savings due to precautionary motives, and thus to higher growth rates (see below).

18. Results of household surveys in sub-Saharan Africa suggest that not only do the poor sell agricultural output, but that tradable products, both exports and food crops, constitute a significant share of their agricultural earnings (Sahn et al., 1997, p. 32).

19. In contrast to some other studies, inflation in Bleaney's regressions loses its significance when the indicator of real exchange rate variability is introduced.

20. Londoño and Székely argued that this outcome may be explained in part by the fact that the poor are less well equipped to cope with economic shocks and that incomes of the poor are substantially more sensitive to changes in aggregate income than upper-income groups.

21. As discussed in detail by Agénor (2001a), two factors may compound the incidence of a credit crunch induced by information problems: the degree of concentration in the financial system, and the fact that small and medium-size firms tend to be more dependent on bank credit than large firms.

22. In principle, the possibility of binding borrowing constraints in adverse state of nature does not, by itself, result in an asymmetric effect. Households may 'internalize' state-dependent credit constraints by deciding, in response to income risk, to accumulate more assets or engage in precautionary savings in 'good' times in order to shelter consumption in 'bad' times. Recent evidence on this type of ex ante riskmitigating strategy is provided by Agénor and Aizenman (2000) for sub-Saharan Africa.

23. See Agénor (1996) for a detailed overview of the literature, and Bigsten and Horton (1998) for a survey of labor markets in sub-Saharan Africa. See also Horton et al. (1994) and the World Bank (1995). Marquez and Pagés-Serra (1998) review regulations governing hiring, firing, overtime work, social security contributions, minimum wages and collective bargaining in Latin America, and examines their impact on labor market outcomes. Edwards and Cox Edward (2000) discuss the case of Chile.

24. The informal sector can be defined in various ways. A common definition is that it includes self-employed workers (except for professionals) unpaid family workers, workers employed in small firms (less than, say, 5 or 6 workers), and those working in the trade and services sector without a proper contract.

25. Demery and Addison (1994) provide a partial equilibrium analysis of the role of the labor market in the transmission process of expenditure-switching policies.

26. The model could be extended, along the lines described in Agénor (2002), to introduce a trade union in the formal sector.

27. The model can be extented to account for the existence of a sector producing importables, but at the cost of greater complexity.

28. Note that the assumed technology implies that skilled and unskilled labor are Edgeworth complements.

29. An alternative way to introduce efficiency considerations in the formal sector would be to assume that production requires (as noted earlier) skilled labor to operate physical capital. Firms would then set wages to minimize turnover costs. Assuming that the quit rate is a function of the consumption wage would yield results that are qualitatively similar to those described below (see Agénor, 2001b). 
30. The condition that the minimum wage be higher than the informal sector wage is necessary to prevent a corner solution in which unskilled workers have no incentive to seek employment in the formal economy.

31. An alternative approach (at this level of abstraction) would be to assume that all unskilled workers, in both the formal and informal sectors, are poor. As noted earlier, the empirical evidence suggests indeed that the average number of years of schooling of the poor tends to be much lower than that of the total workforce. However, the approach adopted here is also consistent with the evidence that suggests a concentration of urban poverty in the informal sector.

32. More generally, it could be assumed that the upper-income household holds, in addition to foreign bonds, domestic assets (such as land). To avoid complicating the analysis further, domestic sources of wealth accumulation are ignored in what follows.

33. Life-cycle models would predict a relationship between consumption and lifetime wealth, rather than with income and current wealth. However, in the presence of liquidity constraints, current income would also affect expenditure. See the evidence for developing countries discussed by Khayum and Baffoe-Bonnie (1994) and Veidyanathan (1993), or the literature reviews in Agénor (2000, Chapter 1) and Agénor and Montiel (1999, ch. 3).

34. Evidence supporting this hypothesis is provided by Hirata and Humphrey (1991) for Brazil, Horton et al. (1994), and Banerjee and Bucci (1995) for India. Agénor (1996) provides a review of the evidence on skilled unemployment in developing countries. In general, of course, whether skilled workers who are not successful in applying for a job in the formal sector decide to seek employment in the informal economy depends on factors such as the efficiency of on-the-job search activities, demotivation effects, and the degree of support from relatives.

35. In what follows, all derivatives are evaluated at initial values of wages and the real exchange rate equal to unity.

36. Using (21), the equilibrium condition of the market for informal sector goods can be rewritten as, using (13):

$$
(1-\delta)\left\{\frac{\omega_{N}\left(z, n_{U}^{s}\right) z}{\eta}\right\}^{\eta /(\eta-1)}=\delta z\left\{\alpha\left[Y_{X}^{s}\left(z ; \omega_{m}\right)+i^{*} B^{*}-T\right]+v B^{*}\right\}
$$

which can be solved for $z$ as a function of $n_{U}^{s}$ and $B^{*}$, as well as the exogenous variables $\omega_{m}$, and $i^{*}$.

37. See Bhattacharya (1993) for a review of the literature on the Harris-Todaro model and, for a more critical view, Stark (1991). Note that in the present setup the Harris-Todaro framework is used to explain migration flows between the (urban) informal sector and the (urban) formal sector, rather than migration between the rural and the urban sectors.

38. In practice, a large proportion of government spending consists of outlays on nontraded goods and services. This is hard to account for in the present setting, because there is only one home good, produced in the informal sector.

39. Appendices A and B are available from the author upon request.

40. Because there is no unemployment benefit scheme in the present framework, unemployed workers in the long run are implicitly assumed to either turn to a subsistence activity (home production) or to rely on relatives for their survival. 
41. As indicated in (21), for a given level of $n_{U}^{s}, \omega_{N}$ must exactly offset movements in $z$. However, $\omega_{N}$ depends also on $n_{U}^{s}$; the rise in $n_{U}^{s}$ puts upward pressure on informal sector wages.

42. See Cardoso (1992) and Morley (1995). Cardoso, for instance, argued that stabilization worsened poverty in Brazil because fiscal adjustment led to a reduction in social expenditures. The issue, however, is quite complex, as discussed earlier.

43. The index combines fiscal, monetary, and exchange rate policies. The fiscal component of the index, for instance, is based on the overall fiscal balance and total revenue. Scores are applied to performance in each of these areas and then added to arrive at the fiscal component of the index. A similar procedure is followed for the exchange rate and monetary components. The aggregate index is a weighted average of performance in each of these three areas of macroeconomic management, with weights given by the relative importance of each component in determining growth, as captured through cross-country regressions.

44. The evidence is based on household sample surveys covering the 1980s and 1990s. As discussed in the first part of this paper, poverty in these countries is predominantly rural, with much of it occurring among small-scale farmers and among the self-employed.

45. Details about IMMPA applications are periodically updated at www.worldbank.org/ immpa.

46. Cross-country regressions have been the subject of criticism for their ad hoc specification and the fragility of many of the results. See Temple $(1999,2000 \mathrm{a})$ for a detailed discussion of the problems that arise in this context and some reasons why they may be, nevertheless, useful tools.

47. In preliminary regressions, two fiscal variables were included to the list of regressors: subsidies and current transfers as a proportion of GDP, and the relative share of transfers and subsidies in public current expenditure. Both variables have a priori an ambiguous effect on poverty. The effect of an across-the-board cut in transfers and subsidies, for instance, may be negative; but to the extent that it is accompanied by better targeting (as noted earlier), there may be no significant effect on the poverty rate. Both variables turned out not to be statistically significant and were thus dropped out from the final results. It is difficult, however, to make much of the fact that public transfers and subsidies are not significant in the regressions; the reason is that the variable may not measure very well what are the subsidies and transfers that actually go to the poor (it includes, for instance, transfers from the government to private and public enterprises).

48. I also tried to interact the degree of openness with the terms of trade indicator, on the ground that in more open economies, changes in the terms of trade may have a larger impact on the poor. The variable turned out to be insignificant.

49. Both the rate of depreciation of the real exchange rate, and the indicator of macroeconomic volatility became insignificant when the sample is split to test for asymmetric effects. The latter retained the correct sign, and was kept in the regression.

50. Note that in the analytical framework described earlier, the size of the labor supply seeking employment in the formal economy does not depend on the speed of adjustment in the long run; only the transitional dynamics are affected.

51. Leontaridi (1998) provides a more detailed discussion of the Dickens-Lang approach.

52. Essentially, if the hypothesis of workers' free choices of sectors is to be accepted, and tastes for the non-pecuniary aspects of employment are independent of individual characteristics (such as the place of residence, marital status, the level of education, 
and so on), then one would expect that the coefficients of the variables describing these characteristics in the switching regression be equal to the coefficients in the two wage equations. Failure to accept this restriction can be viewed as prima facie evidence of non-economic barriers to employment in the formal sector.

53. This discussion assumes that the employment probability in the formal economy does not change significantly in the short run.

\section{References}

Addison, A. and Demery, L. (1994) The poverty effects of adjustment with labor market imperfections. In S. Horton, R. Kanbur and D. Mazumdar (eds), Labor Markets in an Era of Adjustment. Washington DC: World Bank.

Agénor, P. R. (1996) The labor market and economic adjustment. IMF Staff Papers 43: 261-335.

(1997) Capital-Market Imperfections and the Macroeconomic Dynamics of Small Indebted Economies. Princeton Study in International Finance No. 82.

(1999) Stabilization policies, poverty, and the labor market. Unpublished, World Bank.

(2000) The Economics of Adjustment and Growth. San Diego CA: Academic (2nd ed., forthcoming, Harvard University Press).

(2001a) Business cycles, economic crises, and the poor: testing for asymmetric effects. Unpublished, World Bank.

- (2001b) Employment effects of stabilization policies. European Journal of Political Economy 14: 853-75.

(2002) Fiscal adjustment and the labor market in an open economy. Unpublished, World Bank. Journal of Development Economics, forthcoming.

- and Aizenman, J. (1998) Contagion and volatility with imperfect credit markets. IMF Staff Papers 45: 207-35.

(1999) Macroeconomic adjustment with segmented labor markets. Journal of Development Economics 58: 277-96.

(2000) Savings and the terms of trade under borrowing constraints. National Bureau of Economic Research Working Paper No. 774. Forthcoming, Journal of International Economics.

— - Fernandes, R. and Haddad, E. (2002) Analyzing the impact of adjustment policies on the poor: An IMMPA framework for Brazil. Unpublished, World Bank.

- Izquierdo, A. and Fofack, H. (2002) IMMPA: an integrated macroeconomic framework for the analysis of poverty reduction strategies. Unpublished, World Bank. - and Montiel, P. J. (1999) Development Macroeconomics, second edition. Princeton, N.J: Princeton University Press.

Aghion, P., Caroli, E. and Garcia-Penalosa, C. (1999) Inequality and growth: the perspective of the new growth theories. Journal of Economic Literature 37: 1615-60.

Aizenman, J. and Marion, N. P. (1993) Policy uncertainty, persistence and growth. Review of International Economics 1: 145-63.

(1999) Volatility and investment: interpreting evidence from developing countries. Economica 66: 157-79.

Alesina, A. and Perotti, R. (1996) Income distribution, political instability, and investment. European Economic Review 40: 1203-28.

Amadeo, E. and Neri, M. (1997) Macroeconomic policy and poverty in Brazil. Working Paper No. 383, Pontifícia Universidade Católica do Rio de Janeiro.

Anríquez, G., Cowan, K. and De Gregorio, J. (1998) Poverty and macroeconomic policies: Chile 1987-1994. Working Paper No. 27, Universidad de Chile.

(C) Blackwell Publishing Ltd. 2004 
Banerjee, B. and Bucci, G. A. (1995) On-the-job search in a developing country: an analysis based on Indian data on migrants. Economic Development and Cultural Change 43: $565-83$.

Barro, R. J. (1990) Government spending in a simple model of endogenous growth. Journal of Political Economy 98: s103-s25.

(2000) Inequality and growth in a panel of countries. Journal of Economic Growth 5: 5-30.

Bhattacharya, P. (1993) Rural-urban migration in economic development. Journal of Economic Surveys 7: 243-81.

Bigsten, A. and Horton, S. (2001) Labour markets in sub-Saharan Africa. In Ali G. Ali and Erik Thorbecke (eds), Poverty in sub-Saharan Africa. Basingshoke, Macmillan.

Bleaney, M. F. (1996) Macroeconomic stability, investment and growth in developing countries. Journal of Development Economics 48: 461-77.

Bourguignon, F. (2000) The pace of economic growth and poverty reduction. Unpublished, World Bank.

Bourguignon, F., de Melo, J. and Suwa, A. (1991) Distributional effects of adjustment policies: simulations for archetype economies in Africa and Latin America. World Bank Economic Review 5: 315-39.

Breen, R. and Garcia-Penalosa, C. (1999) Income inequality and macroeconomic volatility: an empirical investigation. Unpublished, European University Institute, Oxford.

Bruno, M. and Easterly, W. (1998) Inflation crises and long-run growth. Journal of Monetary Economics 41: 3-26.

Bruno, M., Ravallion, M. and Squire, L. (1998) Equity and growth in developing countries: old and new perspectives on the policy issues. In Vito Tanzi and Ke-young Chu (eds), Income Distribution and High-Quality Growth. Cambridge MA: MIT Press.

Bulir, A. (2001) Income inequality: does inflation matter? IMF Staff Papers 48: 139-59.

Camargo, J. M. and Ferreira, F. H. (2000) The povery reduction strategy of the government of Brazil: a rapid appraisal. Unpublished, Pontificia Universidade Católica do Rio de Janeiro.

Canagarapajah, S. and Mazumdar, D. (1997) Employment, labor markets and poverty in Ghana: a study of changes during economic declines and recovery. Unpublished, World Bank.

Cardoso, E. (1992) Inflation and poverty. Working Paper No. 4006, National Bureau of Economic Research.

Cardoso, E., de Barro, R. P. and Urani, A. (1995) Inflation and unemployment as determinants of income inequality in Brazil: the 1980s. In R. Dornbusch and S. Edwards (eds), Reform, Recovery, and Growth: Latin America and the Middle East. Chicago IL: University of Chicago Press.

Castro-Leal, F., Dayton, J. Demery, L. and Mehra, K. (1999) Public social spending in Africa: do the poor benefit? World Bank Research Observer 14: 49-72.

Choi, S., Smith, B. D. and Boyd, J. H. (1996) Inflation, financial markets, and capital formation. Review, Federal Reserve Bank of St. Louis, 9-35.

De Janvry, A. and Sadoulet, E. (2000) Growth, poverty, and inequality in Latin America: a causal analysis. Review of Income and Wealth 46: 267-87.

Demery, L. and Squire, L. (1996) Macroeconomic adjustment and poverty in Africa: an emerging picture. World Bank Research Observer 11: 39-59.

Dickens, W. T. and Lang, K. (1985) A test of dual labor market theory. American Economic Review 75: 792-805.

Dixit, A. and Pindyck, R. S. (1994) Investment under Uncertainty. Princeton, NJ: Princeton University Press.

Dollar, D. and Kraay, A. (2001) Growth is good for the poor. Policy Resarch Working Paper No. 2587, World Bank. 
Dorosh, P. A. and Sahn, D. E. (2000) A general equilibrium analysis of the effect of macroeconomic adjustment on poverty in Africa. Journal of Policy Modeling 22: 753-76.

Duryea, S. and Székely, M. (1998) Labor markets in Latin America: a supply-side story. Working Paper No. 374, Inter-American Development Bank.

Easterly, W. (1993) How much do distortions affect growth? Journal of Monetary Economics 32: $187-212$.

- (2001) The effect of International Monetary Fund and World Bank programs on poverty. Policy Research Working Paper No. 2517, World Bank.

Easterly, W. and Fischer, S. (2001) Inflation and the poor. Journal of Money, Credit, and Banking 33: 160-79.

Edwards, S. and Edwards A. Cox (2000) Economic reforms and labour markets: policy issues and lessons from Chile. Economic Policy 15: 181-230.

Fallon, P. R. and Lucas, R. E. B. (1993) Job security regulations and the dynamic demand for industrial labor in India and Zimbabwe. Journal of Development Economics 40: 241-75.

Fallon, P. R. and Riveros, L. A. (1989) Adjustment and the labor market. PRE Working Paper No. 214. World Bank.

Fields, G. S. (2001) Distribution and Development: a New Look at the Developing World. Cambridge MA: MIT Press.

Fishlow, A. (1995) Inequality, poverty and growth: where do we stand? In M. Bruno and B. Pleskovic (eds), Annual World Bank Conference on Development Economics. Washington DC: World Bank.

Galor, O. and Zeira, J. (1993) Income distribution and macroeconomics. Review of Economic Studies 60: 35-52.

Gaviria, A. (2001) Household responses to adverse income shocks in Latin America. Working Paper No 455, Inter-American Development Bank.

Gerson, P. R. (1998) Poverty, income distribution, and economic policy in the Philippines. Working Paper No. 98/20.

Gylfason, T. (1998) Output gains from economic stabilization. Journal of Development Economics 56: 81-96.

Grootaert, C. (1992) The position of migrants in the urban informal labour market in Côte d'Ivoire. Journal of African Economies 1: 416-45.

_ (1997) The determinants of poverty in Côte d'Ivoire. Journal of African Economies 6: 169-96.

Harris, J. and Todaro, M. P. (1970) Migration, unemployment and development: a twosector analysis. American Economic Review 60: 126-43.

Hirata, H. and Humphrey, J. (1991) Workers' response to job loss: female and male industrial workers in Brazil. World Development 19: 671-82.

Hoddinot, J. (1996) Wages and unemployment in an urban African labour market. Economic Journal 106: 1610-26.

Horton, S., Kanbur, R. and Mazumdar, D. (1994) Overview. In S. Horton, R. Kanbur and D. Mazumdar (eds), Labor Markets in an Era of Adjustment, Vol. I. Washington, DC: World Bank.

Infante, R. (1995) Labour market, urban poverty, and adjustment: new challenges and policy options. In G. Rodgers and R. van der Hoeven (eds), The Poverty Agenda: Trends and Policy Options. Geneva: International Institute for Labour Studies.

Jaffee, D. and Stiglitz, J. (1990) Credit rationing. In B. M. Friedman and F. H. Hahn (eds), Handbook of Monetary Economics, Vol. II. Amsterdam: North Holland.

Kanbur, R. (2000) Income distribution and development. In A. B. Atkinson and F. Bourguignon (eds), Handbook of Income Distribution. Amsterdam: North Holland.

Khayum, M. and Baffoe-Bonnie, J. (1994) Intertemporal consumer behavior in developing countries. Unpublished, Pennsylvania State University. 
Leontaridi, M. (1998) Segmented labor markets: theory and evidence. Journal of Economic Surveys 12: 63-101.

Li, G., Steele, D. and Glewwe, P. (1999) Distribution of government education expenditures in developing countries. Unpublished, World Bank.

Loayza, N. V. (1996) The economics of the informal sector: a simple model and some empirical evidence from Latin America. Carnegie-Rochester Conference Series on Public Policy, 45.

Lofgren, H. (2001) External shocks and domestic poverty alleviation: simulations with a CGE model of Malawi. TMD Discussion Paper No. 71, International Food Policy Research Institute.

Londoño, J. L. and Székely, M. (1997) Distributional surprises after a decade of reforms: Latin America in the nineties. Working Paper No. 352, Inter-American Development Bank.

- (2000) Persistent poverty and excess inequality: Latin America, 1970-1995. Journal of Applied Economics 3: 93-134.

Lora, E. and Olivera, M. (1998) Macro policy and employment problems in Latin America. Working Paper No. 372, Inter-American Development Bank.

Lustig, N. (2000) Crises and the poor: socially responsible macroeconomics. Working paper No. POV-108, Inter-American Development Bank.

Maechler, A. and Roland-Host, D. W. (1995) Empirical specifications for a general equilibrium analysis of labor market policies and adjustments. Technical Paper No. 106, Organization for Economic Cooperation and Economic Development.

Marquez, G. and Lora, E. (1998) The employment problem in Latin America: perceptions and stylized facts. Working Paper No. 371, Inter-American Development Bank.

Marquez, G. and Pagés-Serra, C. (1998) Ties that bind: employment protection and labor market outcomes in Latin America. Working Paper No. 373, Inter-American Development Bank.

Mazumdar, D. (1993) Wages and employment in Kenya. Unpublished, Africa Region's Chief Economist's Ofice, World Bank.

- (1994) The structure of wages in African manufacturing. Unpublished, World Bank.

Morley, S. A. (1995) Poverty and Inequality in Latin America: the Impact of Adjustment and Recovery in the 1980s. Baltimore MD: Johns Hopkins University Press.

Neri, M. and Thomas, M. (2000) Household educational responses to labor-market shocks in Brazil: 1982-99. Unpublished, World Bank.

Ramey, G. and Ramey, V. A. (1995) Cross-country evidence on the link between volatility and growth. American Economic Review 85: 1138-51.

Ravallion, M., (1994) Poverty Comparisons. Chur, Switzerland: Harwood Press. (2000) Are the poor protected from budget cuts? Theory and evidence for Argentina. Working Paper No: 2391, World Bank.

Rodrik, D. (1998) Trade policy and economic performance in sub-Saharan Africa. Working Paper No. 6562, National Bureau of Economic Research.

Romer, C. D. and Romer, D. H. (1998) Monetary policy and the well-being of the poor. Working Paper No. 6793, National Bureau of Economic Research.

Sahn, D. E. (1996) Economic reform and poverty: an overview. In David E. Sahn (ed.), Economic Reform and the Poor in Africa. Oxford: Clarendon Press.

Sahn, D. E., Dorosh, P. A.and Younger, S. D. (1997) Structural Adjustment Reconsidered: Economic Policy and Poverty in Africa. Cambridge: Cambridge University Press.

Sarel, M. (1996) Nonlinear effects of inflation on economic growth. IMF Staff Papers 43: $199-215$.

Sarris, A. H. (1996) Macroeconomic polices and household welfare in Tanzania. In D. E. Sahn (ed.) Economic Reform and the Poor in Africa. Oxford: Clarendon Press.

Stark, O. (1991) The Migration of Labor. Oxford: Basil Blackwell. 
Subramanian, S. (1996) Vulnerability to price shocks under alternative policies in Cameroon. In D. E. Sahn (ed.) Economic Reform and the Poor in Africa. Oxford: Clarendon Press.

Székely, M. (2001) The 1990s in Latin America: another decade of persistent inequality, but with somewhat lower poverty. Working Paper No 454, Inter-American Development Bank.

Temple, J. (1999) The new growth evidence. Journal of Economic Literature 37: 112-56. - (2000a) Growth regressions and what the textbooks don't tell you. Bulletin of Economic Research 52: 181-205.

- (2000b) Inflation and growth: stories short and tall. Journal of Economic Surveys 14: $332-426$.

Veidyanathan, G. (1993) Consumption, liquidity constraints and economic development. Journal of Macroeconomics 15: 591-610.

Wodon, Q., Castro-Fernandez, R., Lee, K., Lopez-Acevedo, G., Siaens, C., Sobrado, C. and Tre, J. P. (2001) Poverty in Latin America: trends (1986-1998) and determinants. Unpublished, World Bank.

World Bank (1995) Workers in an Integrating World. Washington DC: World Development Report.

- (1997) Poverty in Côte d'Ivoire: a framework for action. Unpublished, World Bank.

(1998) Attacking Poverty. Washington DC: World Development Report. (2000) Attacking Poverty. New York: Oxford University Press. 